\title{
Membrane Deployment Technology Development at DLR for Solar Sails and Large-Scale Photovoltaics
}

\author{
Tom Spröwitz, Patric Seefeldt, Peter Spietz, Jan Thimo Grundmann, Rico \\ Jahnke, Eugen Mikulz, Siebo Reershemius, Thomas Renger, Kaname Sasaki, \\ Norbert Tóth \\ DLR Institute of Space Systems \\ Robert-Hooke-Strasse 7 \\ 28359 Bremen, \\ Germany \\ Tom.Sproewitz@dlr.de, +49-421-24420-1237 \\ Patric.Seefeldt@dlr.de, +49-421-24420-1609 \\ Peter.Spietz@dlr.de,jan.grundmann@dlr.de, Rico.Jahnke@dlr.de, \\ Eugen.Mikulz@dlr.de, Siebo.Reershemius@dlr.de, Thomas.Renger@dlr.de, \\ Kaname.Sasaki@dlr.de, Norbert.Toth@dlr.de \\ Maciej Sznajder \\ DLR Institute of Space Systems \\ Robert-Hooke-Strasse 7 \\ 28359 Bremen, \\ Germany \\ +49-421-24420-1623 \\ Maciej.Sznajder@dlr.de \\ \& \\ Institute of Physics \\ University of Zielona Góra \\ Szafrana 4a \\ 65-069 Zielona Góra \\ Poland
}

\begin{abstract}
Following the highly successful flight of the first interplanetary solar sail, JAXA's IKAROS, with missions in the pipeline such as NASA's NEASCOUT nanospacecraft solar sail and JAXA's Solar Power Sail solar-electric propelled mission to a Jupiter Trojan asteroid, and on the back-ground of the ever increasing power demand of GEO satellites now including all-electric spacecraft, there is renewed interest in large lightweight structures in space. Among these, deployable membrane or 'gossamer' structures can provide very large functional area units for innovative space applications which can be stowed into the limited volumes of launch vehicle fairings as well as secondary payload launch slots, depending on the scale of the mission. Large area structures such as solar sails or high-power photovoltaic generators require a technology that allows their controlled and thereby safe deployment. Before employing such technology for a dedicated science or commercial mission, it is necessary, to demonstrate its reliability, i.e., TRL 6 or higher.
\end{abstract}

A reliable technology that enables controlled deployment was developed in the Gossamer-1 solar sail deployment demonstrator project of the German Aerospace Center, DLR, including verification of its functionality with various laboratory tests to qualify the hardware for a first demonstration in low Earth orbit. We provide an overview of the Gossamer-1 hardware development and qualification campaign. The design is based on a crossed boom configuration with triangular sail segments. Employing engineering models, all aspects of the deployment were tested under ambient environment. Several components were also subjected to environmental qualification testing.

An innovative stowing and deployment strategy for a controlled deployment and the required mechanisms are described. The tests conducted provide insight into the deployment process and allow a mechanical characterization of this process, in particular the measurement of the deployment forces.

The stowing and deployment strategy was verified by tests with an engineering qualification model of one out of four Gossamer-1 deployment units. According to a test-as-you-fly approach the tests included vibration tests, venting, thermalvacuum tests and ambient deployment. In these tests the deployment strategy proved to be suitable for a controlled deployment of gossamer spacecraft, and deployment on system level was demonstrated to be robust and controllable.

The Gossamer-1 solar sail membranes were also equipped with small thin-film photovoltaic arrays intended to supply the core spacecraft. In our follow-on project GoSoLAR, the focus is now entirely on deployment systems for huge thin-film photovoltaic arrays. Based on the GossAMER-1 experience, deployment technology and qualification strategies, new technologies for the integration of thin-film photovoltaics are being developed and qualified for a first in-orbit technology demonstration within five years. Main objective is the further development of deployment technology for a $25 \mathrm{~m}^{2}$ gossamer 
solar power generator and a flexible photovoltaic membrane. GoSolAR enables a wider range of deployment concepts beyond solar sail optimized methods. It uses the $S^{2}$ TEP bus system developed at the Institute of Space Systems as part of the DLR satellite roadmap.

\section{TABLE OF CONTENTS}

1. INTRODUCTION....................................1

2. GoSSAMER BoOM \& SAIL TeChNOLOGY........2

3. DEPLOYMENT TECHNOLOGY TESTING.........9

4. Gossamer Solar Sail Performance........15

5. CONCLUSION AND OUTLOOK..................16

ACKNOWLEDGEMENTS...........................17

REFERENCES.....................................17

BIOGRAPHY ..................................19

\section{INTRODUCTION}

In the last years, the DLR (German Aerospace Center) has pursued the development of a scalable deployment technology for gossamer spacecraft systems, suitable for autonomous and controlled deployment. A summary of those developments is given in this paper. While the focus was on solar sails and thin-film photovoltaics, the aim of the development is to provide a scalable technology for deployable membranes for various space applications. The development was made within the DLR project GOSSAMER1. It was initiated with the goal of developing the required deployment technology and its demonstration in LEO (Low Earth Orbit) by means of a scaled demonstrator as shown in Figure 1.

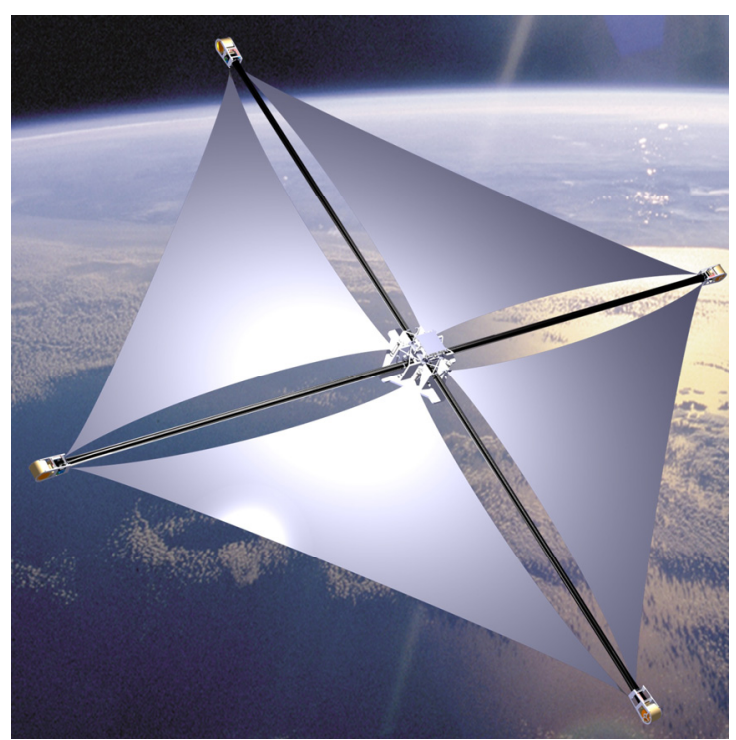

Fig. 1. GOSSAMER-1 demonstrator, artist's rendering

\subsection{Previous development at DLR}

The development of solar sail technologies in Europe and at DLR goes back to the 1990 s when the first solar sail breadboards were tested using a $20 \mathrm{~m}$ by $20 \mathrm{~m}$ square, i.e., $(20 \mathrm{~m})^{2}$ sail in a joint DLR, NASA/JPL and ESA project.

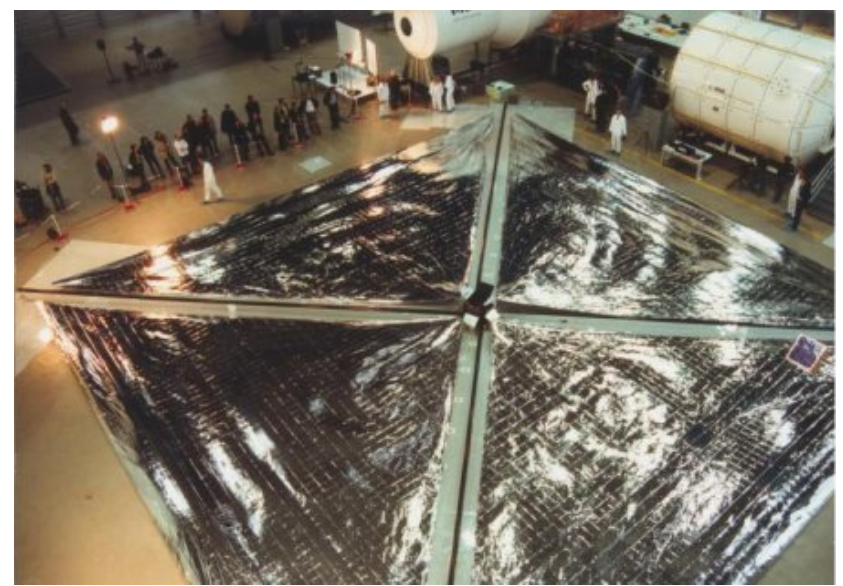

Fig. 2. Ground deployment test of a $(20 \mathrm{~m})^{2}$ sail, DLR Cologne, in the EAC hall (note space station practice modules in the background) December $17^{\text {th }}, 1999$

It was followed by development projects like ODISSEE [1] and GEOSAIL [2]. The ground demonstration (Figure 2) is presented by Leipold in [3] and the study activities are summarized in [4].

\subsection{GOSSAMER-1development concept}

GOSSAMER-1 employs the knowledge gained from these projects and reuses the previously developed CFRP (Carbonfiber Reinforced Plastic) booms, as well as state of the art aluminum coated polyimide foil. With respect to the deployment and the evolved mechanisms, it was recognized that previous strategies had disadvantages with respect to controlling and automatizing the deployment. In addition, previous projects aimed for the realization of a complete solar sail mission with a scientific payload. This increased mission complexity and cost. Ultimately, the earlier projects were not able to realize a full mission. In consequence, a step-wise development focusing on the deployment technology was pursued starting with GosSAMER-1. It is a low cost technology demonstrator as part of an intended three-step scalable technology development covering membranes, booms, photovoltaics and their corresponding mechanisms. Scalable means that GOSSAMER-1 is a $(5 \mathrm{~m})^{2}$ technology demonstrator using technology that is suited to build the control methods demonstrator GOSSAMER-2 with $(20 \ldots 25 \mathrm{~m})^{2}$, and GoSSAMER-3 with $(\sim 50 \mathrm{~m})^{2}$ proving the principle in a full demonstration mission near Earth. [5] These were the 3 steps envisaged in the DLR-ESA Gossamer Roadmap. [6][7]

The DLR-ESA Gossamer Roadmap - The Gossamer Roadmap was an ambitious plan started in 2009 to advance 
the development of solar sail technology in a technologyonly development path independently from any dedicated science mission. Although in the end, even its first step was not followed through to its flight opportunity, it still represents the important steps that the development of any solar sail technology will have to follow. The following tables 1 and 2 provide an overview of the envisaged spacecraft at the beginning and at the end of the GOSSAMER1 project.

Tab. 1. The Gossamer Roadmap and its spacecraft as first envisaged in 2009, adapted from [6][7].

\begin{tabular}{|l|c|c|c|}
\hline spacecraft & GOSSAMER-1 & GOSSAMER-2 & GOSSAMER-3 \\
\hline launch in & 2013 & 2014 & 2015 \\
\hline deployed size & $(5 \mathrm{~m})^{2}$ & $(20 \mathrm{~m})^{2}$ & $(50 \mathrm{~m})^{2}$ \\
\hline initial orbit & $320 \mathrm{~km}$ & $500 \mathrm{~km}$ & $>10000 \mathrm{~km}$ \\
\hline mass & $24 \mathrm{~kg}$ & $57 \mathrm{~kg}$ & $\sim 80 \mathrm{~kg}$ \\
\hline $\begin{array}{l}\text { characteristic } \\
\text { acceleration }\end{array}$ & $\mathrm{n} / \mathrm{a}$ & measurable & $>0.1 \mathrm{~mm} / \mathrm{s}^{2}$ \\
\hline container vol. & $45 \cdot 45 \cdot 50 \mathrm{~cm}^{3}$ & $50 \cdot 50 \cdot 60 \mathrm{~cm}^{3}$ & $(100 \mathrm{~cm})^{3}$ \\
\hline sail foil & $7.5 \mu \mathrm{m}$ & $<7.5 \mu \mathrm{m}$ & $<<7.5 \mu \mathrm{m}$ \\
\hline design lifetime & days & $\sim 4$ weeks & $\sim 600$ days \\
\hline $\begin{array}{l}\text { mission } \\
\text { objectives }\end{array}$ & deployment & $\begin{array}{c}\text { limited orbit } \\
\text { and attitude } \\
\text { control }\end{array}$ & $\begin{array}{c}\text { full orbit and } \\
\text { attitude control, } \\
\text { lunar fly-by }\end{array}$ \\
\hline $\begin{array}{l}\text { observation } \\
\text { payload }\end{array}$ & $\geq 2$ on-board \\
cameras & $\begin{array}{c}\geq 2 \text { cameras, } \\
\text { inspector } \\
\text { cubesat }\end{array}$ & $\begin{array}{c}\geq 2 \text { cameras, } \\
\text { inspector cube, } \\
\text { narrow-angle } \\
\text { camera }\end{array}$ \\
\hline
\end{tabular}

At the conclusion of the development of GOSSAMER-1, a design for a complete 4-quadrant sail Proto-Flight Model (PFM) free-flyer spacecraft had been prepared to the degree of definition which is required to build a 2-quadrant, single boom Engineering Qualification Model (EQM) to test and validate all critical technologies sufficiently to proceed with PFM procurement and integration. The DLR Institute of Space Systems had meanwhile demonstrated the capability to complete a similarly challenging small spacecraft in 2 years, from the authorisation to release sufficient means and manpower to procure and build, to the delivery of a Flight Model (FM) in the MASCOT asteroid lander project for the Japanese HAYABUSA2 sample-return mission currently en route to asteroid (162173) Ryugu. [8][9][10][11]

\subsection{Large membrane stowing methods \& requirements}

Studies investigating how to stow membranes for space applications go back to the 1980s. Miura [12] already stated general requirements for the packaging of membranes for space applications. He described that folding and deployment are two phases of a reversible process. Reversible means, that the chosen stowing strategy must allow an autonomous deployment in space. It should be supplemented that the stowed sail needs to withstand all launch loads, i.e. shock, vibrations and fast decompression. Such a qualification process is described in [13].
Tab. 2. The Gossamer Roadmap spacecraft as last envisaged in mid-2014.

\begin{tabular}{|c|c|c|c|}
\hline spacecraft & GOSSAMER-1 & GOSSAMER-2 & GOSSAMER-3 \\
\hline launch in & $\geq$ end 2016 & $\geq 2018$ & $\geq 2020$ \\
\hline size & $(5 \mathrm{~m})^{2}$ & $(20 \ldots 25 \mathrm{~m})^{2}$ & approx. $(50 \mathrm{~m})^{2}$ \\
\hline $\begin{array}{l}\text { initial } \\
\text { orbit }\end{array}$ & $\begin{array}{l}\text { drag dominant } \\
300 \times 700 \mathrm{~km}\end{array}$ & $\begin{array}{l}\text { SRP dominant } \\
(\geq \sim 700 \mathrm{~km})\end{array}$ & $\begin{array}{l}\text { spiral-up } \\
\text { feasible }\end{array}$ \\
\hline char.accel & $\mathrm{n} / \mathrm{a}$ & $6 \sigma$ measurable & $>0.1 \mathrm{~mm} / \mathrm{s}^{2}$ \\
\hline $\begin{array}{l}\text { launch } \\
\text { volume }\end{array}$ & $\varnothing 80 \cdot 50 \mathrm{~cm}^{3}$ & \multicolumn{2}{|c|}{$\begin{array}{c}\leq 80 \cdot 80 \cdot 100 \mathrm{~cm}^{3} \\
\text { ASAP \& ESPA compatible }\end{array}$} \\
\hline $\begin{array}{l}\text { launch } \\
\text { mass }\end{array}$ & $\begin{array}{c}37.6 \mathrm{~kg} \\
\text { with margins }\end{array}$ & \multicolumn{2}{|c|}{$\begin{array}{c}\leq 200 \mathrm{~kg} \\
\text { ASAP \& } \text { ESPA compatible }\end{array}$} \\
\hline sail foil & $7.5 \mu \mathrm{m}$ & $2.5 . .7 .5 \mu \mathrm{m}$ & $\leq 2.5 \mu \mathrm{m}$ \\
\hline $\begin{array}{l}\text { design } \\
\text { lifetime }\end{array}$ & 90 days & $\sim 1$ year & $\sim 1 \ldots 2$ years \\
\hline $\begin{array}{l}\text { sailcraft } \\
\text { orbital } \\
\text { lifetime }\end{array}$ & $\begin{array}{l}\sim 90 \text { days } \\
\text { predicted }\end{array}$ & $\begin{array}{c}\leq 25 \text { years @ } \\
\leq 2000 \mathrm{~km}, \\
\text { indefinte above }\end{array}$ & $\begin{array}{c}\text { indefinite } \\
\text { (heliocentric) }\end{array}$ \\
\hline $\begin{array}{l}\text { BSDUs } \\
\text { orbital } \\
\text { lifetime }\end{array}$ & $\begin{array}{l}<10 \text { years } \\
\text { predicted }\end{array}$ & $\begin{array}{c}\leq 25 \text { years @ } \\
\leq 2000 \mathrm{~km}, \\
\text { indefinte above }\end{array}$ & $\begin{array}{l}\text { indefinite } \\
\text { (likely } \\
\text { geocentric) }\end{array}$ \\
\hline $\begin{array}{l}\text { mission } \\
\text { objectives }\end{array}$ & $\begin{array}{c}\text { fully } \\
\text { documented } \\
\text { controlled } \\
\text { deployment }\end{array}$ & $\begin{array}{l}\text { comparison of } \\
\text { several full } \\
\text { attitude control } \\
\text { methods, partial } \\
\text { orbit control }\end{array}$ & $\begin{array}{c}\text { full orbit and } \\
\text { attitude control, } \\
\text { Earth-departure } \\
\text { and lunar fly-by } \\
\text { capability }\end{array}$ \\
\hline $\begin{array}{l}\text { monitor } \\
\text { payload }\end{array}$ & $\begin{array}{c}6 \text { on-board } \\
\text { cameras on } \\
\text { CSCU \& } \\
\text { BSDUs }\end{array}$ & $\begin{array}{c}\geq 2 \text { wide-angle } \\
\text { cameras on } \\
\text { CSCU, sail \& } \\
\text { plasma } \\
\text { environment } \\
\text { (TBC) }\end{array}$ & $\begin{array}{l}\geq 1 \text { wide-angle } \\
\text { camera, } \\
1 \text { narrow-angle } \\
\text { camera on } \\
\text { CSCU } \\
\text { sail monitoring } \\
\text { sail environment }\end{array}$ \\
\hline
\end{tabular}

With respect to the differentiation of folding strategies, Miura [12] distinguished one-dimensional and twodimensional folding techniques. The differentiation is made by the in-plane dimensions of the membrane that shrink due to the folding process. Due to the size of the membranes considered, it is of course always necessary to reduce both dimensions. This can be achieved by combining two onedimensional folding processes or by employing an additional coiling of the previously folded membrane. Guest [14] describes patterns allowing the wrapping of a membrane around a central hub, and De Focatiis [15] presents different folding patterns based on the folding of tree leaves. Double zig-zag folding patterns, sometimes referred to as frog-leg folding, were employed, for example, by Leipold [3] and Stohlman [16]. A combined folding and central coiling of a sail membrane split into four triangular segments was implemented for JAXA's IKAROS sail [17] and for a Cubesat and on a CubeSat level this is presented in [18].

GOSSAMER-1 deployment strategy selection - Pursuing the goal of having a controllable configuration during the deployment, the main difference with the GOSSAMER-1 deployment strategy is that the membrane is stowed on four deployment units that, during deployment, move away from the central unit (the center of the deployed sail). Figure 3 illustrates the deployment process. By uncoiling the booms, 
the deployment units move outwards, thereby uncoiling and unfolding the sail segments simultaneously. The sail segments' folded parts remain taut between their respective deployment units advancing along their booms. Thus, the risk of sail entanglement is removed. [19][20]

GOSSAMER concept of sailcraft mass reduction - After the sail deployment is completed, the sail segments are separated from the deployment mechanism and the deployment units are jettisoned. Thereby, all elements are removed which are required only for deployment. This enables a membrane supported by a rigid boom structure in a lightweight flight configuration while avoiding many of the disadvantages of boom-less centrifugal or inflatable deployment methods. This unique combination of features is expected to provide robust and carefree handling sailcraft with the capability to accomodate full 6DOF control and the potential for high agility, if and as their mission requires it.

\section{Gossamer Boom \& SAIL TeChnOlogy}

GOSSAMER-1 is based on a crossed boom configuration with four sail segments. At the geometric center of the spacecraft, the booms' crossing point, the Central Spacecraft Unit (CSCU) carries the satellite's main bus system, including all electronics covering command and data handling, power system, as well as ground communications system. Four Boom and Sail Deployment Units (BSDUs) are mounted on the booms, one on each boom. In the stowed configuration, they are mechanically locked and electrically (power and data) connected to the central unit. For deployment, the deployment units are unlocked and disconnected from the central unit and move outward, thereby simultaneously deploying the booms and the sail segments. During deployment, communication with the central unit is achieved via a wireless on-board communications system. Each BSDU has its own power system and on-board computer, as there are no wired connections foreseen in the booms. By this, a controlled and automatized deployment is realized that contrasts to the achievements of other projects like JAXA's IKAROS (see [17]) and NASA's NanoSail-D (see [21]). The deployment process is monitored by analyzing various characteristics and can be stopped and resumed at any time, if required. [5][22]

The satellite has an estimated mass of about $30 \mathrm{~kg}$ and the compact launch configuration shown in Figure 3(a) has a maximum width of approximately $790 \mathrm{~mm}$ and a height of $500 \mathrm{~mm}$. Figure 4 provides an overview of the system components. It was planned to launch the GOSSAMER-1 satellite as secondary payload within the EC FP7 Project QB50 [23]. However, due to prioritization of other competing projects, it was not possible to build the complete satellite and as a consequence the launch opportunity with QB50 could not be used. It is likely that the PSLV-XL C38 launch of June $23^{\text {rd }}, 2017$, would have carried the GOSSAMER-1 PFM in free-flyer configuration to a circular $500 \mathrm{~km}$ Sun-synchronous orbit if the project had proceeded as envisaged in mid-2014.
Achieved were the design of a technology demonstration mission and the development of a new deployment strategy that meets the above stated goals. Engineering models of all hardware were built and subject to various tests.

The deployment technology is described in the following section. The tests conducted with the engineering models of the deployment technology are presented in Section 3. The tests show the functionality of the GOSSAMER-1 deployment technology, including mechanisms and electronics.

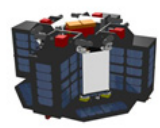

(a) Launch Configuration

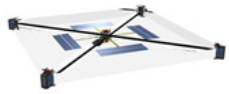

(c) Deployed

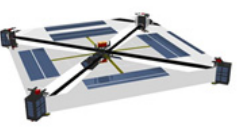

(b) During deployment

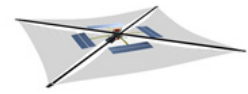

(d) Deployed with jettisoned mechanisms
Fig. 3. GOSSAMER-1 deployment sequence

In the following paragraphs, the subcomponents and mechanisms enabling the deployment will be described in further detail.

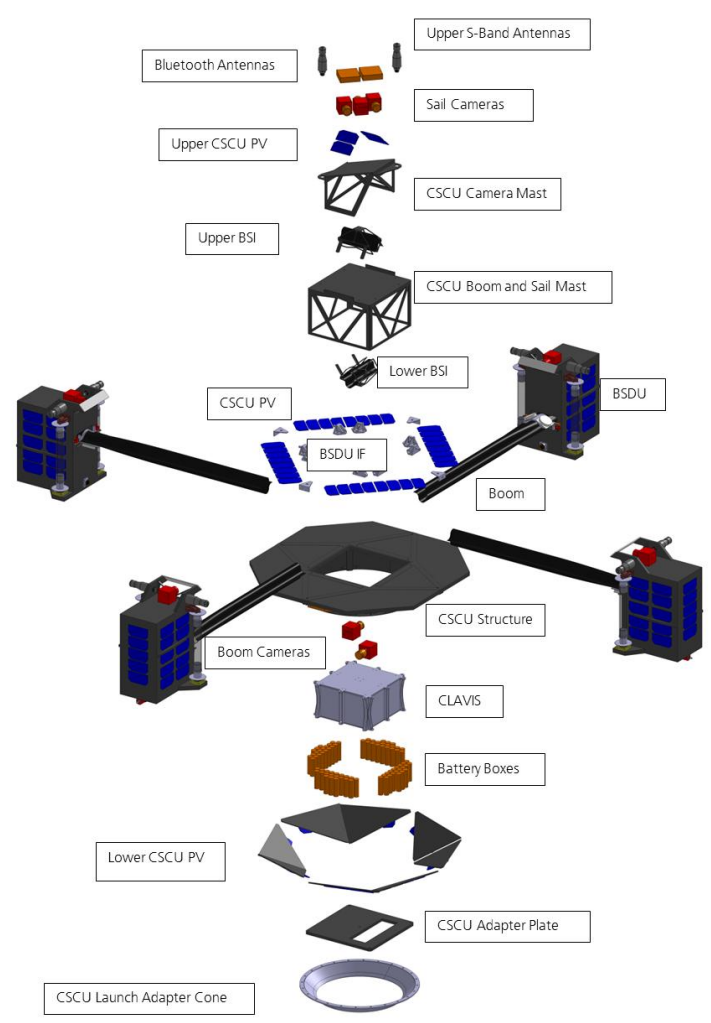

Fig. 4. GosSAMER-1 exploded view 


\subsection{Booms}

GOSSAMER-1 makes use of light-weight coilable CFRP booms, also referred to as collapsible tube masts, as shown in Figure 5. Two booms are configured in a cross-like arrangement with a vertical displacement. The booms are mounted to the CSCU via a Boom-Spacecraft Interface (BSI) as shown in Figure 6.

DLR previously developed and investigated the technology in precursor projects, e.g. ODISSEE [1] and GEOSAIL [2]. The cross section of the boom was chosen according to the smallest possible dimensions that allow coiling of the boom without reaching critical stress levels in the material and adhesive layers. The length of one full-diagonal boom is 8.6 $\mathrm{m}$. It is determined by the chosen sail size of $5 \mathrm{~m} \times 5 \mathrm{~m}$ and the necessary remaining length for the jettisoning of the BSDUs.

During the deployment, the boom cross section is not constant along the boom. The diameter increases in $y-$ direction along the deployed length, starting with the flat configuration at the point where the boom is coiled inside the BSDU (see Figure 5). It takes more than one meter until the boom's cross section in y-direction is comparable to the deployed configuration and a small distortion of the cross section can be observed along the whole boom length. Due to the reduced geometrical moments of inertia, respectively bending stiffness, the boom section closest to the boom hub at which the boom is uncoiled is most sensitive to mechanical loads and therefore requires a linear guiding.

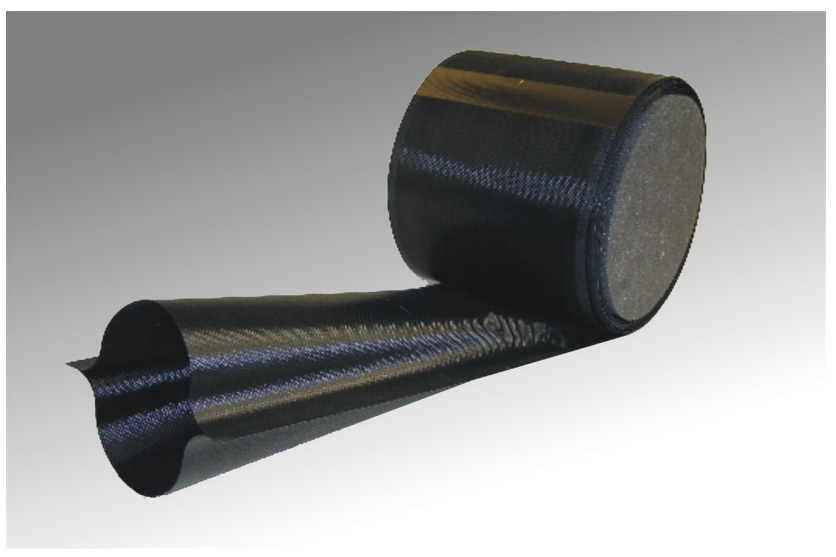

Fig. 5. Coilable thin shell CFRP booms, partially stowed boom with larger cross section compared to GOSSAMER1 , unfolding $\Omega$-shaped in $y$-direction (here vertical)

\subsection{Sails}

A preliminary material selection was presented by Seefeldt [24]. For the sail membranes, the $7.5 \mu \mathrm{m}$ thick polyimide foil Upilex-S® covered on both sides with $100 \mathrm{~nm}$ vacuum deposited aluminum was chosen. It is delivered on a roll of a width of $1016 \mathrm{~mm}$. Additionally, samples were coated with silicon oxide on top of the aluminum to increase the infrared emittance which is still under investigation. The sails are manufactured by using $3 \mathrm{M} \AA$ transfer adhesive tape
966. First, five sheets are prepared, one with the photovoltaics. By bonding the edges with the transfer adhesive after folding them over, a reinforcement against cracks is achieved. The adhesive tape is also used to mount interfaces and attach the photovoltaics with its harness. In a final step all segments are bonded together in order to achieve the required sail size.

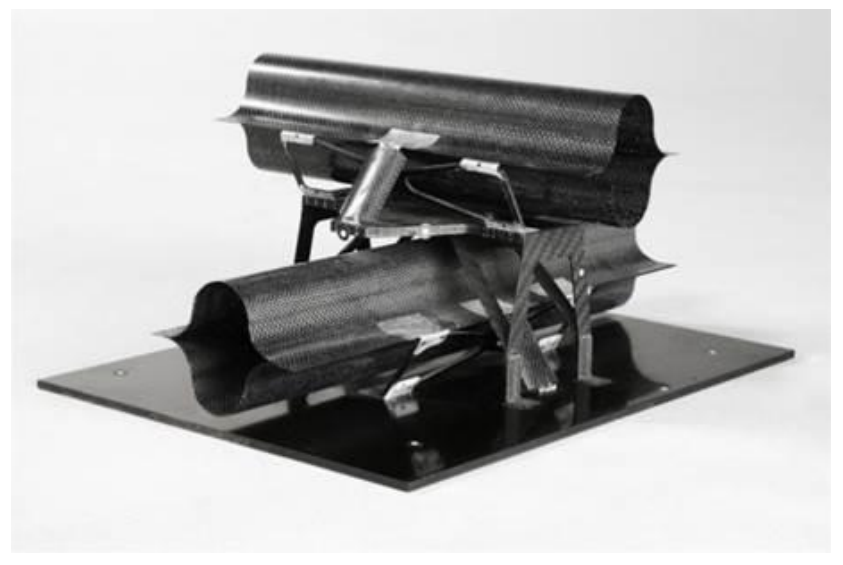

Fig. 6. Boom-Spacecraft Interface for two crossed CFRP booms with vertical displacement

Within the GEOSAIL precursor project [2], the transfer adhesive was tested for low temperatures down to $-142{ }^{\circ} \mathrm{C}$. In addition to that work, a short term duration test in a furnace was conducted, reaching temperatures up to $230{ }^{\circ} \mathrm{C}$. In these tests, the adhesive bonding was loaded with 0.9 $\mathrm{N} / \mathrm{cm}^{2}$ (shear) and withstood the high temperature. The loading was roughly twice as high as the limit specified in the data sheet. In contrast to the design presented by Seefeldt [24], a rigging is no longer used in the present design. Instead, the interface points are reinforced with a thicker copper coated foil, similar to what is used for flexible PCBs (Printed Circuit Boards). The connection between those reinforced interfaces and the interface to the boom and the CSCU are made of a $0.45 \mathrm{~mm}$ stainless steel ropes.

The stowing strategy is shown in Figure 7. The triangular segments are folded in a zig-zag pattern and coiled onto two spools. The spools are mounted on two neighboring BSDUs (see Figure 3(a)). Folding and coiling the sail this way is a key for controlled deployment. During sail deployment, only the minimal required amount of sail is uncoiled from the sail spools the deployed sail is always under tension. The stowing strategy was subject to intensive testing, presented by Seefeldt [13]. The tests are summarized in Section 3.

The photovoltaic part of the prototype sail is shown in Figure 8. The thin-film photovoltaics are located at the inner corner, close to the CSCU. These consist of small experimental modules that are bonded to the sails employing the abovementioned transfer adhesive. The modules are electrically contacted to a flexible PCB harness in the middle of the triangle. Note that the modules are 
currently experimental prototypes that are the subject of ongoing studies.

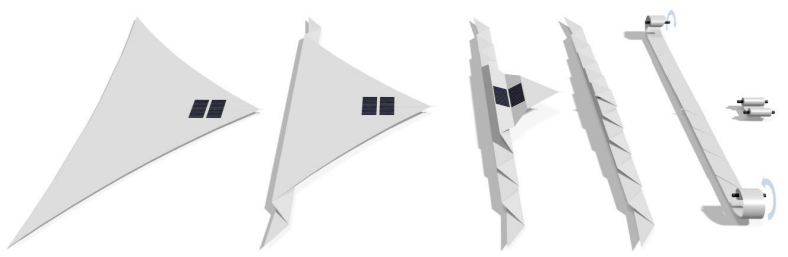

Fig. 7. Gossamer-1 sail stowing strategy for one of the four segments

One of the first considerations for the stowing technique was that rectangular, not-folded areas for the photovoltaics were needed. Additionally, the photovoltaic strings were mounted such that they were lying face to face on top of each other. This resulted from electrical insulating considerations. Therefore, the specific peculiarities of the photovoltaics alone already caused the consideration of a combined folding and coiling strategy. The harness of the on-membrane photovoltaics is lead along the sail segment centre line to the CSCU, in parallel to the mechanical fixation. Figure 9 shows the stowed configuration.

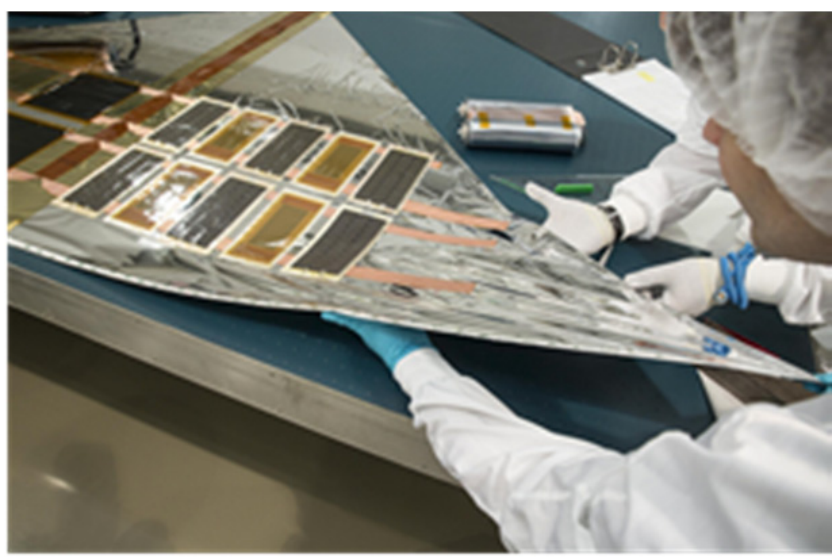

Fig. 8. Thin-film photovoltaic integrated on the GOSSAMER-1 EQM sail foil

The development of membrane-based huge photovoltaic arrays is presently continued at the DLR Institute of Space Systems in the GOSOLAR project. [25]

\subsection{Boom and Sail Deployment Mechanisms}

As already mentioned, the deployment is driven by BSDUs that are moving away from the CSCU. Booms and sail segments are thereby deployed at the same time. Figure 10 shows one BSDU (without the sails) during the whole deployment process. For clear representation, only one BSDU without sail segments is shown. The engineering model of the boom deployment mechanism was also presented by Straubel [26].
In the stowed configuration (see Figure 10a)) launch locks secure the BSDU onto the CSCU which are released prior to deployment. The deployment is driven by a belt which is coiled on the boom hub together with the boom. At the very end of the boom, a small piece of Velcro connects the belt to the boom. The boom and consequently the sails are deployed by pulling-off the belt from the boom hub and thereby uncoiling the boom. As the boom deploys it pushes the BSDU away from the CSCU, which in turn uncoils the sail segments from the sail spools. The transferred shear load is well supported by the Velcro and the compression loads between the coiled layers also prevent premature separation of both Velcro parts by pressing both components together.

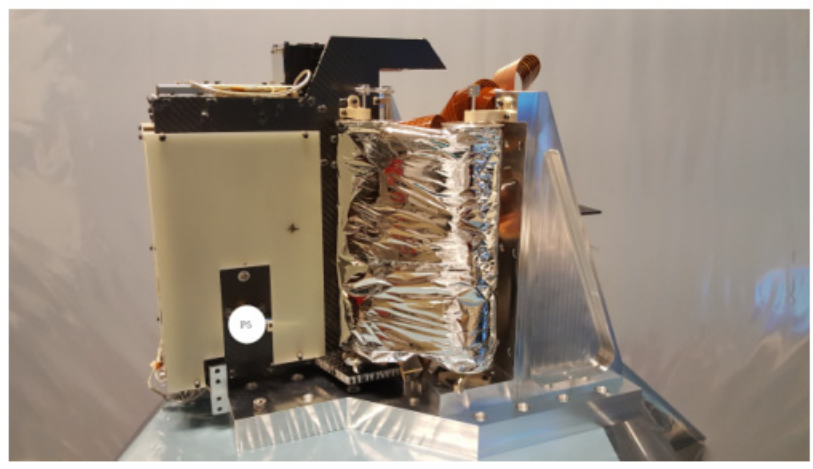

(a) Side view, sail membrane includes functional photovoltaic.

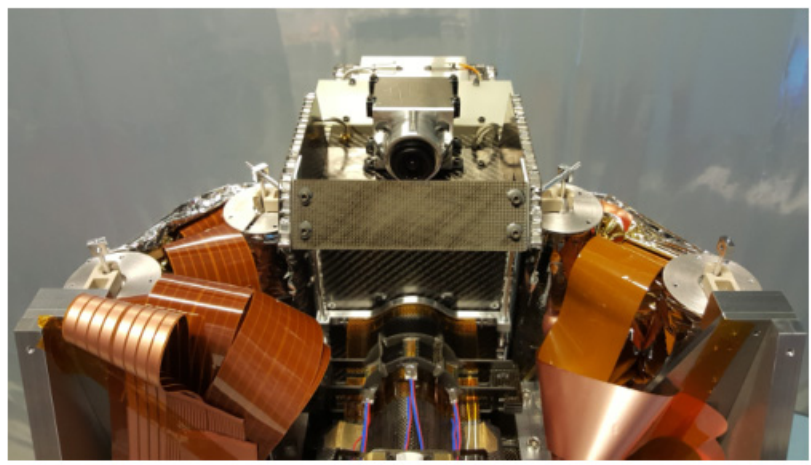

(c) Front view (from CSCU).

Fig. 9. Engineering-qualification model of the GOSSAMER-1 deployment unit with one boom and two sail segments

The uncoiling of the belt is driven by the belt winding mechanism (BWM) using an electric motor. To prevent uncontrolled deployment of the booms and sails, e.g. by stored elastic energy, the boom hub and the sail spools have brake mechanisms as described in the following dedicated paragraphs. 


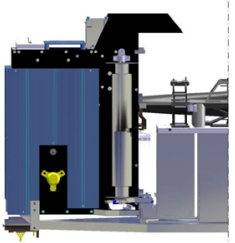

(a) Launch Configuration

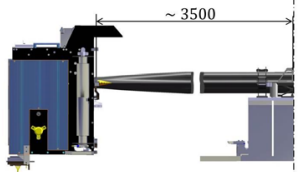

(c) Sails fully deployed;

BSFR is locked by tape spring on boom

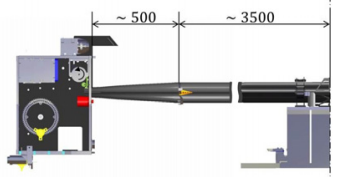

(e) Belt connected by Velcro is separated from boom

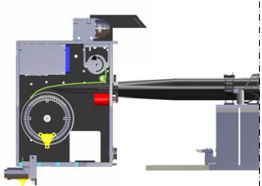

(b) BSDU is released and deployment started; the belt

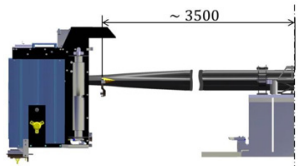

(d) BSFR separated and remaining boom is deployed

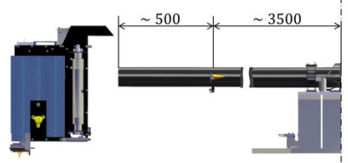

(f) BSDU is jettisoned and drifts away (green) is coiled by BWM

Fig. 10. BSDU deployment sequence. For clear representation, one BSDU without sail segments is shown

To achieve the jettisoning function of the BSDU, the Boom Sail Fixation Ring (BSFR) provides the interface between the outer sail corners and the boom. During sail deployment, the BSFR is attached to the BSDU with the boom running through the ring-like shape of the BSFR. Once the sail is fully deployed (Figure 10c)), the BSFR is locked to the boom and mechanically separated from the BSDU (Figure 10d)). At this point the BWM drive unit can be engaged again to further deploy the remaining boom for a complete jettisoning (Figure 10e) and 10f). At this final stage of the deployment, the tip of the boom is deployed by transferring the deployment load purely through the Velcro. As the Velcro passes the pulley and the Velcro loading transforms from shear loading into peel loading both parts are separated without a decisive deceleration of the BSDU. The BSDU and boom are separated completely, and the BSDU maintains the previously gained kinetic energy and floats away as indicated by Figure 10f).

The EQM of the BSDU features all mechanisms, structural elements, mechanisms and actuators as well as membranes, avionics, wireless communication and sensoring. Mechanisms, launch locks and sensoring are described in more detail in the following subsections. Figures 11 and 12 gives an impression on the component density inside the BSDU, which is in itself a complete space system.

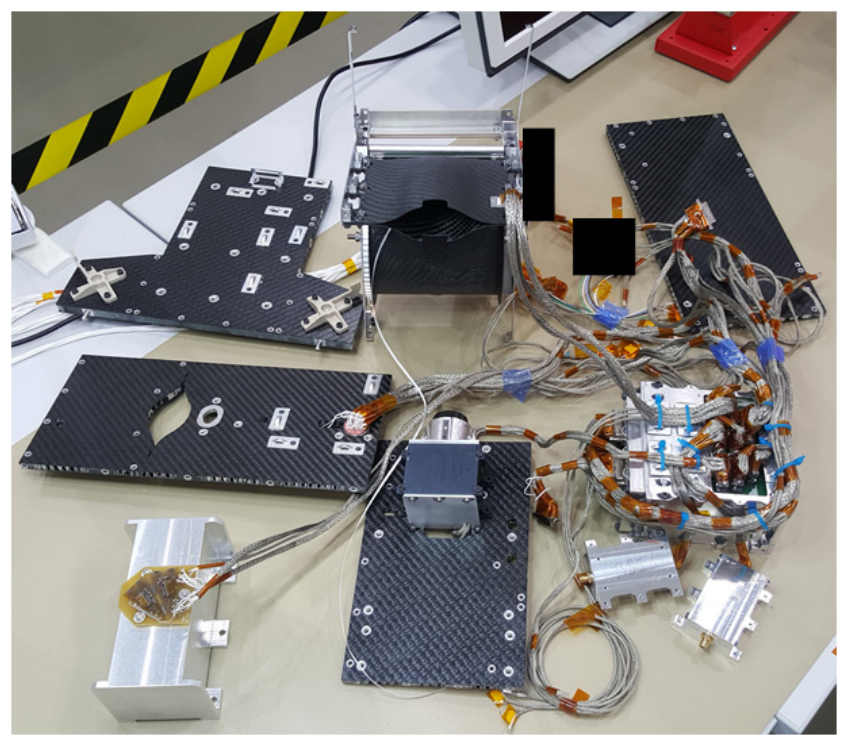

Fig. 11. BSDU EQM hardware during integration for system level testing, exploded view (ITAR elements blacked out)

Belt Winding Mechanism - As explained above, the BWM pulls off a $0.03 \mathrm{~mm}$ thick stainless steel belt that is coiled onto the Boom Hub together with the boom. The BWM consists of an electrical motor, a belt spool with a diameter of $40 \mathrm{~mm}$, and a freewheel to ensure that the belt is always under tension. The winding spool is directly mounted on the output shaft of the gearbox employing a feather key. The freewheel is made of a gear with pitched teeth that is part of the winding spool and an engaging copper beryllium spring plate (blue part). The belt is guided by a diverting pulley to the BWM spool.

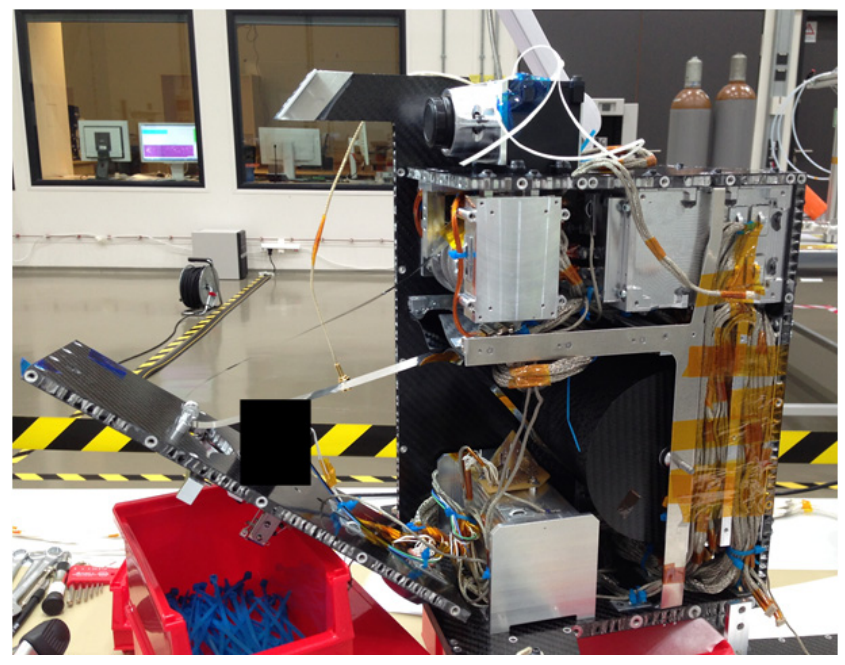

Fig. 12. BSDU EQM hardware during final integration (ITAR elements blacked out)

The motor of the winding mechanism has to overcome torques induced by the boom hub, the boom guidance and the sail spool. A critical point is that motors used under 
vacuum conditions easily overheat. As a consequence, the resulting life cycle needs to be critically evaluated. During deployment the motor has to run at low speed for a relatively long time. After a longer break for cooling down the motors during jettisoning will take place with high motor speed for a short period.

The Phytron VSS32 motor with a GPL32 gear box was chosen for the engineering model. For the EQM, the company produced a customized Version of the VSS32 motor with a GPL22 gear box. In order to withstand the high mechanical launch loads, the design of motor and gearbox was made more robust. That led to a slight increase in size, which was compensated by the smaller GPL22 so that it still fits into the dedicated space inside the BSDU. The change in the gear box led to a change in the transmission ratio from 50:1 to 49:1. Under vacuum, the motor can run $6 \mathrm{rpm}$ up to $7.5 \mathrm{~min}$ for deployment, and 30 rpm up to $1 \mathrm{~min}$ for jettison until it overheats. Considering the spool diameter of $40 \mathrm{~mm}$, the corresponding deployment speeds are $1.3 \cdot 10^{-2} \mathrm{~m} / \mathrm{s}$ for the slower mode and $6.3 \cdot 10^{-2}$ $\mathrm{m} / \mathrm{s}$ for the faster. It is desirable to use the slowest deployment speed possible in order to reduce inertial loads during deployment. In order to deploy the boom to $3.8 \mathrm{~m}$, the locking point of the BSFR, in the maximum motor operating time for slower speeds of $7.5 \mathrm{~min}$, the deployment speed is determined to be $0.84 \cdot 10^{-2} \mathrm{~m} / \mathrm{s}$. A torque budget, derived from force measurements with the engineering models, is given in Section 3.2.

Boom Hub - The boom hub is a rotatable mounted spool on which boom and belt are coiled. It is mounted with a plain bearing. The design is presented in Figure 13. On one side of the boom hub there is a gear with additional conical holes. For launch, the rotation of the spool is locked by a conical pin that locks into the holes on the side of the gear. A pin puller (highlighted in yellow) releases the gear rotation in orbit.

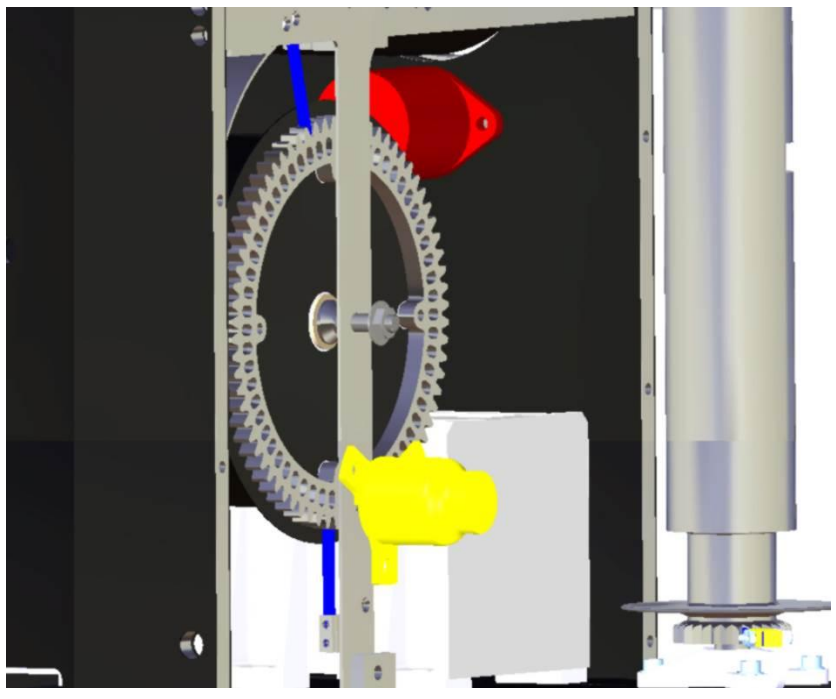

Fig. 13. Boom hub with gear and leafe springs (blue). The pin-puller (yellow) lock into the holes of the gear
In order to have a controlled deployment that can be stopped and resumed at any time, and to counteract the selfdeployment of the boom due to stored elastic energy, the boom hub includes the aforementioned brake mechanism. It employs copper-beryllium plates (highlighted blue) that engage into the gear. Through the deformation of those leaf springs when rotating the hub, an oscillating torque with a maximum of about $0.25 \mathrm{Nm}$ is generated.

Boom Sail Fixation Ring - The Boom Sail Fixation Ring is the boom-sail interface. During deployment the boom slides through the BSFR. At the point where the sails are fully deployed, the sails must be mounted to the booms. This is achieved by attaching the BSFR at this position to the boom by employing tape springs that are glued onto the boom. During deployment, the BSDU with the BSFR moves across the tape spring until the BSFR locks in right behind the spring.

After the ring is locked into its final position, the separation (Phase 5) between BSFR and BSDU takes place. This is achieved by employing the Ejection and Release Mechanism (ERM) E250 STD from TiNi Aerospace Inc. It opens the mounting between BSFR and the BSDU. Afterwards the BSDU can move further, deploying the last centimeters of the booms leaving the BSFR with the mounted sail at the fixation point.

Sail Spools - Each of the four sail quadrants is folded and coiled onto two sail spools, which are mounted on two adjacent BSDUs. When uncoiling the sail segment, the spool with the sail interface rotates around the truss-like structure connected to the BSFR (Figure 14(a)). After the sail segment is uncoiled, the truss-like structure directly mounts the sail through the sail interface to the BSFR (Figure 14(b)). After the separation from the BSFR the BSDU with the sail spools drives further along the booms, thereby separating the sail spool from the truss like structure that is mounting the sail to the BSFR (Figure 14(c)). The patent of Seefeldt and Spietz [27] can be reviewed for details of the mechanism function.

During launch, a gear wheel on the sail spool bottom side is used to lock the spool with a corresponding counterpart mounted on the CSCU. A leaf spring engaging the gear adds an oscillating break torque of approximately $0.035 \mathrm{Nm}$ at maximum. This is required during deployment to ensure that the sail does not slip off of the spool. The mechanism allows a complete stop within the deployment process and still has the partly-deployed sail safely mounted.

Launch Locks - During launch, all mechanisms are locked in order to provide a mechanically stable configuration of all parts. An overview of the locking mechanisms employed is provided in Figure 15. 


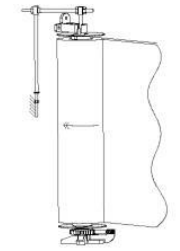

(a) Sail Segment uncoiling

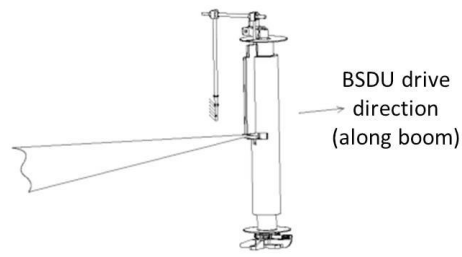

(b) Segment uncoiled with interface to truss structure

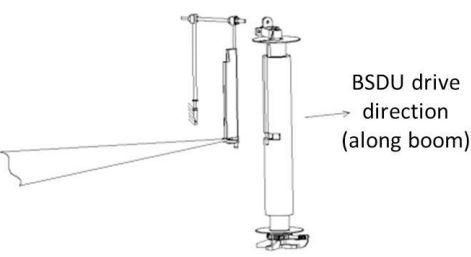

(c) Separated truss structure

Fig. 14. Sail separation sequence

The Boom Hub is locked by a P5 pin puller from TiNi Aerospace, Inc. It is mounted on the outer wall of the BSDU, and the pin is locked into one of the conical holes located around the boom hub gearwheel. In order to simplify the integration, 60 holes allow the hub to be locked in the necessary position. A cone shape for the pin and the holes was chosen in order to avoid clamping of the locked pin (e.g. due to thermal expansion).

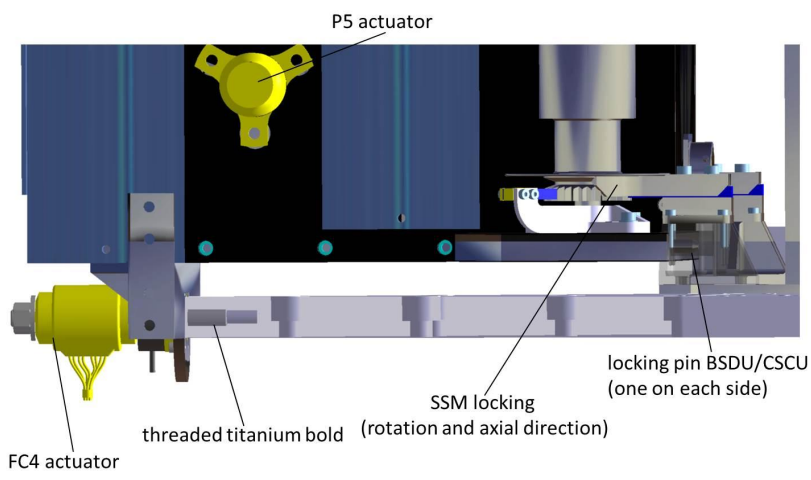

Fig. 15. BSDU Launch Locks

Additionally, a form-fitting locking element ensures the locking of each sail spool by engaging its gear and a circumferential groove in the sail spool's lower end (see Figure 15 on the right).

\subsection{Deployment Monitoring}

An in-orbit demonstration of the deployment technology requires sensors to gather data for the system validation. Therefore, a boom length measurement, a camera system and a measurement of the boom loading using strain gauges was implemented.

Boom length measurement - Strips with reflective markers attached to the boom flanges (see Figure 16) are used to determine the position based on counts of changes in reflectivity with an optoelectronic sensor. Implementing periodically occurring calibration markers and a slight phase shift in the pattern provides higher robustness of position determination.

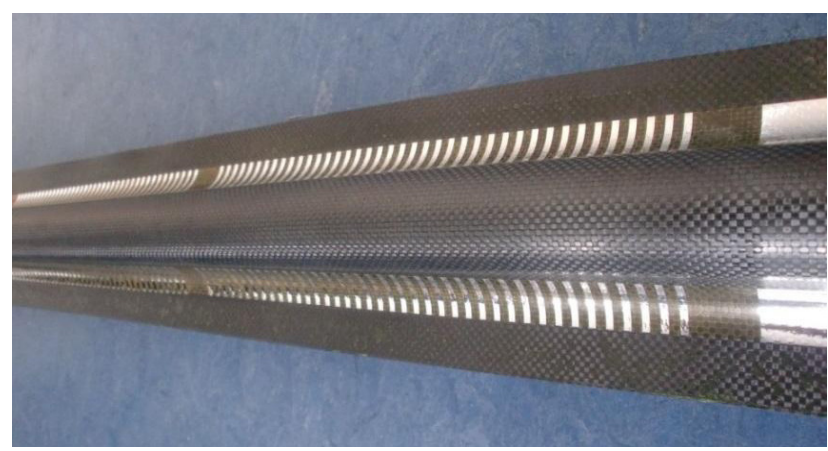

Fig. 16. Reflective marker on the boom

Camera System for Visual Documentation - The camera system consists of 9 cameras with differing focal length. One camera is placed on top of each deployment unit facing inwards and covering the full spacecraft by wide field optics. Three cameras on the central unit facing outwards with wide field optics, covering one sail segment, adjacent booms and deployment units. Two of these are positioned such that stereoscopic viewing is supported. The two remaining cameras on the central unit cover one boom and its deployment unit with a depth of field ranging from roughly the initial unlocking up to the final position.

Boom loading measurement - Boom loads are determined by strain gauges attached to the booms near the BSI. Besides general monitoring for an on-orbit characterization of the deployment system, they are also used to detect boom overload, which would trigger an emergency stop and additional FDIR (Fault Detection, Isolation and Recovery). Zander [28] presented preliminary experiments for future inorbit load and deflection monitoring.

\section{DePloyment TeChnology Testing}

In the order to validate the technology, a series of development as well as qualification tests were performed using different engineering models. The tests ranged from mechanical characterization of booms, sail manufacturing 
and sail folding techniques, to characterization and functional testing of individual mechanisms. A full twosegment system level deployment test under ambient conditions using an engineering model of the BSDU was conducted. Qualification testing of one deployment unit with boom and adjacent sail segments is carried out with the flight representative EQM model. This also includes all electronic subsystems contained in the deployment unit. [29][30]

\subsection{Sail Testing}

Pre-qualification tests were performed with a mechanically flight representative sail packed according to Figure 7 and stowed on two sail spool engineering models. Thin film photovoltaics were simulated by mechanically representative dummies made from flexible PCB material. Harnessing on the sail was accomplished using loosely bundled high-quality industrial PTFE-insulated AWG28 litz wire. The wire type used was previously qualified at system level for MASCOT (see [31]). Following a test-as-you-fly philosophy test were performed starting with a shaker test followed by centrifugal acceleration, fast decompression, and finally deployment under ambient conditions (see Deployment Testing of this Section). The tests were also presented by Seefeldt in [13]. Test loads were based on the launcher load envelope.

All tests except the deployment were conducted with a test adapter specially designed for those tests as shown in Figure 17. It has a representative bearing and locking mechanism for the spools included. For final functional verification, the sail package and sail spools were transferred to the deployment test rig (see Figure 18). To deploy one sail segment two linear drives of $4.5 \mathrm{~m}$ length at a right angle were used. The sail spools were mounted on these units with tri-axial force sensors placed between linear drives and sail spools. The deployment was realized be a computer controlled movement of the linear drives. Different deployment speeds and speed profiles could be tested. The Sail package and sail spools passed the test successfully with no anomalies observed.

\subsection{Engeneering Model Deployment Testing}

Laboratory deployment tests were made at different levels of complexity, starting with individual subsystems up to final full functional system level tests. The goal was the verification of:

the general deployment strategy,

sail stowing and deployment,

boom stowing and deployment,

related force budgets,

mechanism functionality,

the electronics involved (position determination, camera system, on-board wireless communications),

- $\quad$ the deployment logic implemented.

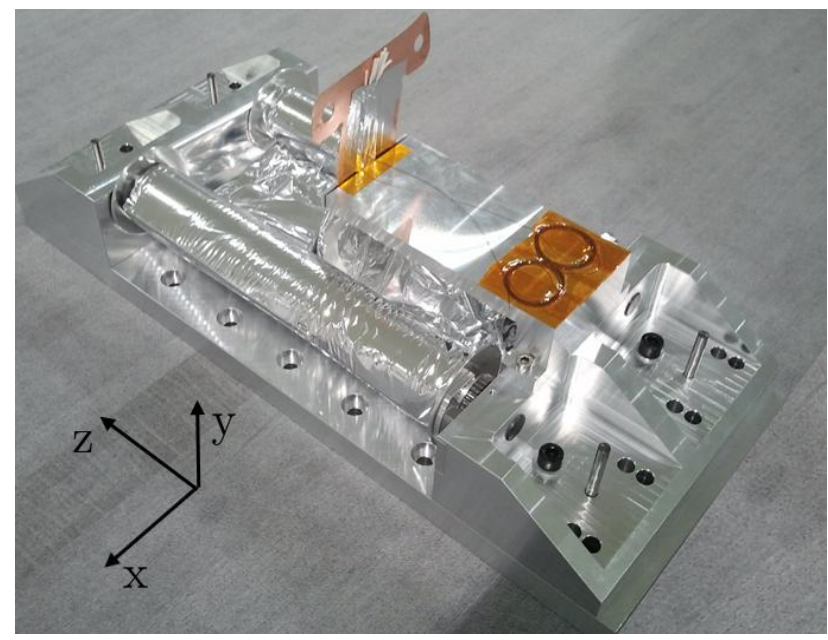

Fig. 17. Sail package mounted on Sail Spool test adapter

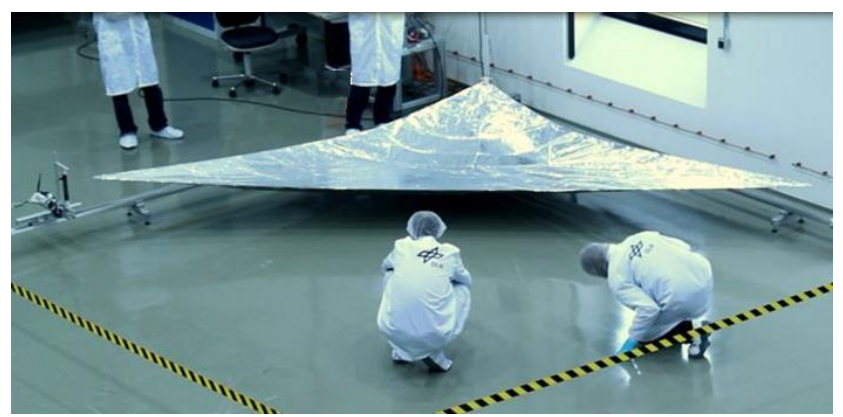

Fig. 18. Deployment test of one sail segment alone without booms and BSDU on Sail deployment test rig

Boom stowing and boom deployment was tested in socalled boom-pull out tests with just a single boom and a mechanically functional representative BSDU. No sails or sail deployment simulators were applied. Oscillations caused by the leaf spring of the boom hub brake mechanism as well as imperfections and inhomogeneity of the material were observed. Values vary between 5 to $15 \mathrm{~N}$ with an approximate average of about $10 \mathrm{~N}$. The results were presented by Straubel in [32].

The test rig, which was used for the sail testing, was extended for the deployment of two sail segments with one boom and one BSDU for system level deployment tests. It consists of two linear drives arranged in a line simulating one full boom diagonal of a GOSSAMER-1 configuration (see Figure 19). This test setup enables a fully functional system level test including mechanisms, electronics and implemented logic.

One boom and BSDU can be tested at right angles between the linear drives (Figure 19). The boom was mounted to a BSI and was deployed by a fully functional BSDU engineering model. The BSDU was supported by a test rig, with air bearings for minimum friction in order to allow free BSDU and boom movement within the sail plane. On each linear drive, a sail spool was mounted on top of a tri-axial 
force sensor. The BSDU was fully equipped including the sail spools on both sides. This setup allowed for the deployment of one boom and both adjacent sail segments and is referred to as one-boom-two-sail-segment system level test. The BSDU was controlled by the on-board wireless communications with a fully functional CSCU electronics system including EGSE and suitable control interfaces. Acquisition of sensor data as well as BSDU camera images was implemented. The data was transferred via the on-board wireless communications system from the BSDU to the CSCU.

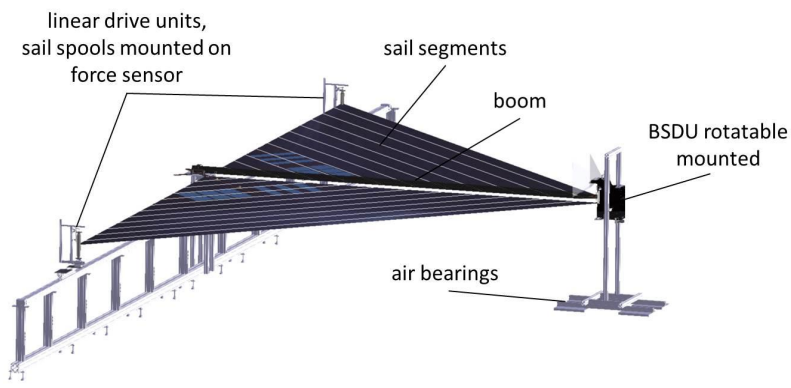

Fig. 19. Test rig for the deployment of two sail segments with one boom and BSDU

Different phases of the deployment test are shown in Figure 20. The deployment is shown in Figure 20(a), followed by the separation Figure 20(b) and the BSDU jettison in Figure 20(c). Figure 20(d) shows an image acquired by the BSDU on-board camera during a deployment test. The same way as for boom pull-out, the sail spools and sail deployment also introduce forces when pulling off the sail from the sail spool. These forces were measured during deployment by force sensors placed between the linear drive units and the corresponding sail spool mount.

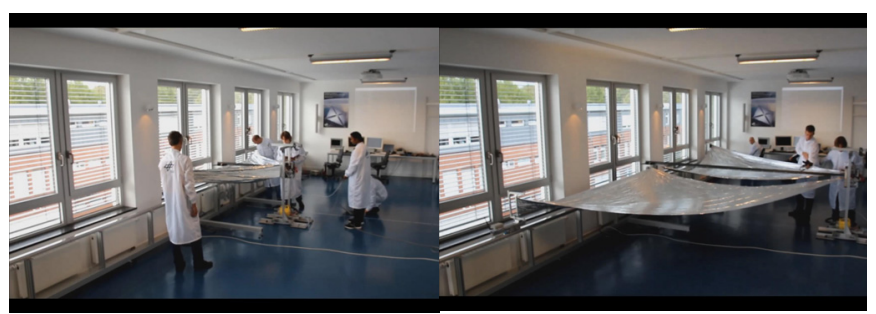

(a) Deployment and

(b) Sail completely acquisition of picture with on board camera

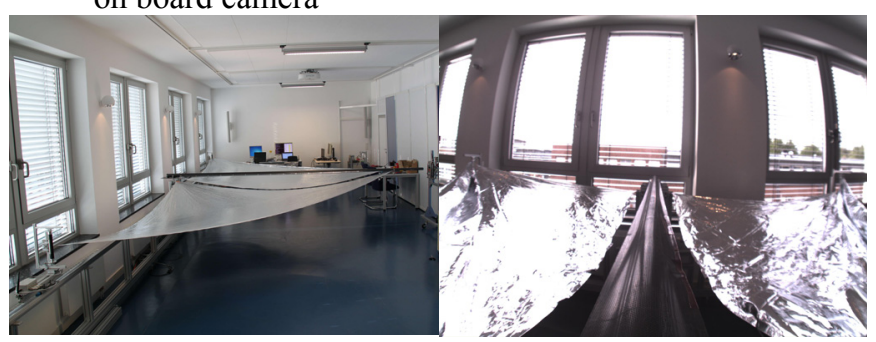

(c) BSDU jettison

(d) On-board camera picture during deployment

Fig. 20. GosSAMER-1 EM deployment test in progress
Data was recorded as a function of time. Maximum values were observed with $2.2 \mathrm{~N}$. This applies to one sail spool. As one BSDU has to pull off two sail halves, this force must be considered twice in the budget, resulting in $4.4 \mathrm{~N}$.

Similar to the boom pull-out, the sail pull-off measurements also showed a fast oscillation caused by the leaf spring brakes at the sail spools. The oscillations are roughly about 1.3 N. Besides a smaller amount of friction between the tip of the spring and the gear, this mainly represents the deformation of the spring. There is a general trend of increasing forces during the sail deployment due to two main effects. The diameter of the sail coiled on the spool is decreasing from about $50 \mathrm{~mm}$ at the beginning to the spool diameter of $35 \mathrm{~mm}$ at the end. This leads to a force increase of about $0.4 \mathrm{~N}$.

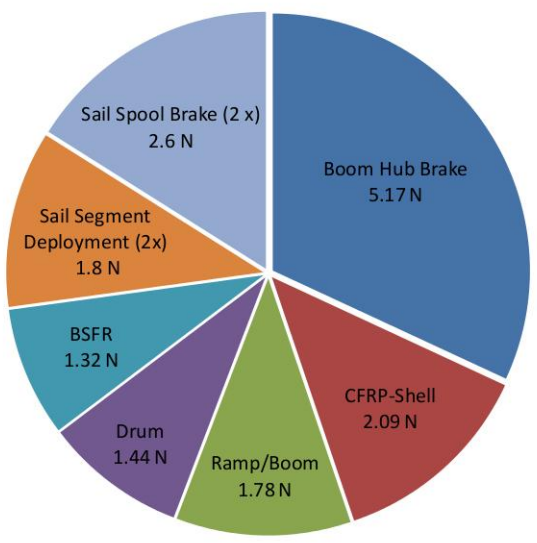

Fig. 21. Composition of the deployment force that is introduced through the BWM

Additionally, the deployed sail introduces tension forces when deployed in the laboratory under gravitation. The highest forces appear at the point shortly before the sail is completely deployed and when jettisoning the BSDU. At both times the force is about $2.2 \mathrm{~N}$. Figure 21 shows the measured contributions to the full force budget. Forces purposely added by the sail spool and boom hub leaf spring brake add up to $5.2 \mathrm{~N}+2.6 \mathrm{~N}=7.8 \mathrm{~N}$, whereas the major friction related contributions of the boom deployment add up to $6.6 \mathrm{~N}$. In addition, the laboratory sail deployment introduces forces of $1.8 \mathrm{~N}$. This is mainly gravitation related, but also includes an unknown fraction of friction force of the sail spool mechanisms. These forces transform into the required drive torque at the gear's axis through multiplication with the radius of the belt winding mechanism's spool of $20 \mathrm{~mm}$. The torques were multiplied with uncertainty and safety factors according to ECSS-EST-01C [33] and sum up to $0.86 \mathrm{Nm}$.

\subsection{System-Level Testing}

System level tests are performed using the flightlike EQM of the deployment system consisting of one BSDU, one Boom and two sail segments partially equipped with 
photovoltaic or representative dummies. Aim of the tests is reaching TRL 5 for the main technologies by testing under representative environmental conditions. The integration of the complete EQM and the sail manufacturing were performed in the ISO 8 integration hall of the DLR Institute of Space Systems. All system level tests were also performed in ISO 8 environment serving as good practical experience for the integration and testing of future deployment systems.

As already mentioned the test sequence was chosen according to the test-as-you-fly philosophy starting with vibration testing, followed by venting testing and thermalvacuum testing including a partial deployment in vacuum at low and high temperatures. The sequence will be concluded with a laboratory full deployment test in the ISO 8 integration hall.

Vibration Testing - Vibration testing was performed on the $11 \mathrm{kN}$ shaker of the institute in ISO 8 environment. The sinusoidal and random vibration loads as shown in Figure 17 are an envelope of the loads of the most probable launchers and are applied to all three test axes. No amplifications were taken into account. The main body of Gossamer-1, the CSCU, was considered to be a stiff body. Figure 23 shows the test setup for the vertical testing of the EQM BSDU with integrated sails on the test adpater. The tests did neither yield structural damages nor did they show frequency shifts larger than 5\% between the different test runs. All functional tests during and after the vibration tests were successful.

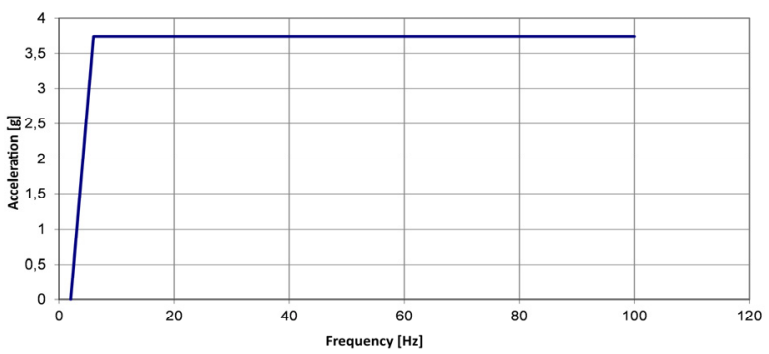

(a) sinusoidal testing

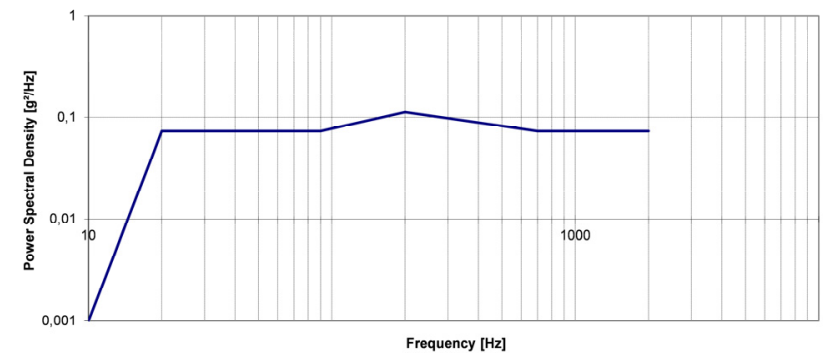

(b) random testing

Fig. 22. Load profiles for the vibration testing

Even though the requested eigenfrequency design criterion with $\geq 100 \mathrm{~Hz}$ could not be fulfilled the analysis and the experimental results show a relatively good agreement as can be seen in Table 3. However, for a better judgement a thourough investigation on the mode shapes needs to be performed.

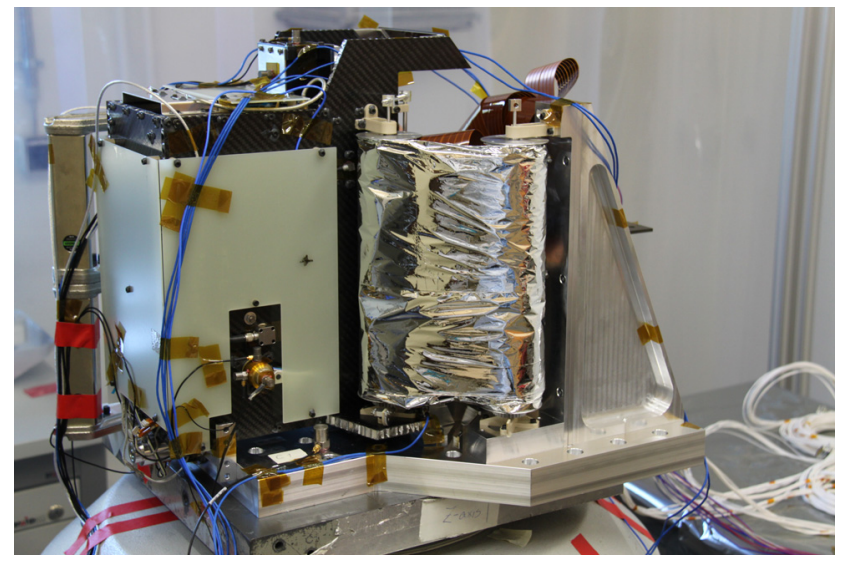

Fig. 23. Shaker test setup for EQM system level test, EQM BSDU mounted on Vibration Shaker

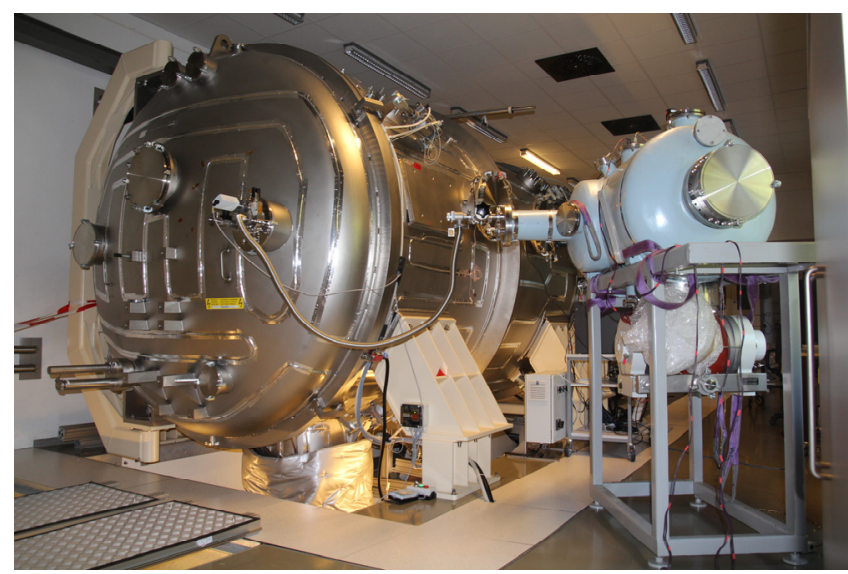

Fig. 24. EQM system level Venting test configuration

Tab. 3. Comparison of numerical and experimental eigenfrequencies

\begin{tabular}{|c|r|r|}
\hline \# of Eigenfrequency & \multicolumn{1}{|c|}{ Analysis } & \multicolumn{1}{|c|}{ Experimental } \\
\hline 1 & $76 \mathrm{~Hz}$ & $60 \mathrm{~Hz}$ \\
\hline 2 & $83 \mathrm{~Hz}$ & $75 \mathrm{~Hz}$ \\
\hline 3 & $230 \mathrm{~Hz}$ & $237 \mathrm{~Hz}$ \\
\hline
\end{tabular}

Venting Testing - Vibration testing is followed by the venting testing. For that purpose the EQM BSDU is placed in a $0.3 \mathrm{~m}^{3}$ test chamber with ambient pressure. This small chamber is connected to the evacuated $17 \mathrm{~m}^{3}$ Space Simulation Chamber of the insitute as shown in Figure 24. By a determined opening of the valve between both chambers the small chamber is rapidly evacuted. Especially for the folded and rolled membrane this load case can be decisive if air is trapped between folds of the sail. 
Figure 25 shows the depressurization curve with maximum pressure differences of up to $70 \mathrm{mbar} / \mathrm{s}$ and reaching a pressure of less than 50 mbar within $45 \mathrm{~s}$. This is compliant with a large number of launcher ascent profiles.

Post test inspections did not reveal any changes or damages on the sail package. A post test functional test of the unit did prove full operability after the test.

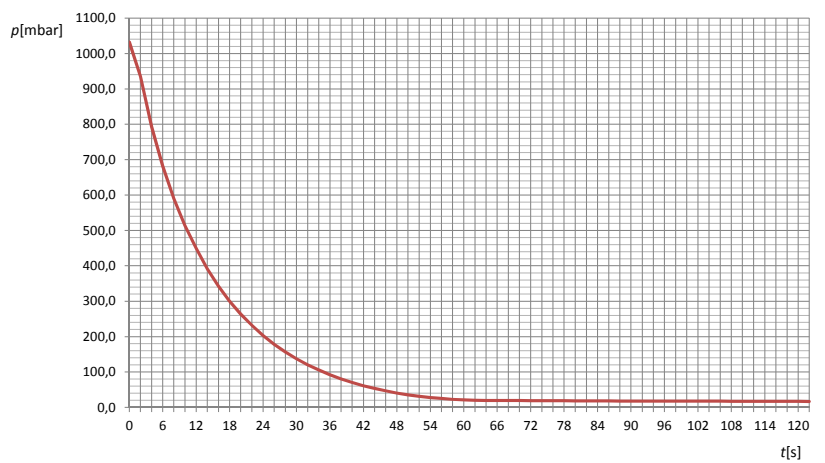

Fig. 25. Depressurization curve

Thermal Vacuum Testing and Partial Deployment - Figure 26 shows the EQM BSDU in its configuration for the thermal vacuum testing. The BSDU itself is placed on a carriage in order to be able to deploy the BSDU for some millimeters after successful actuation of all release mechanisms.

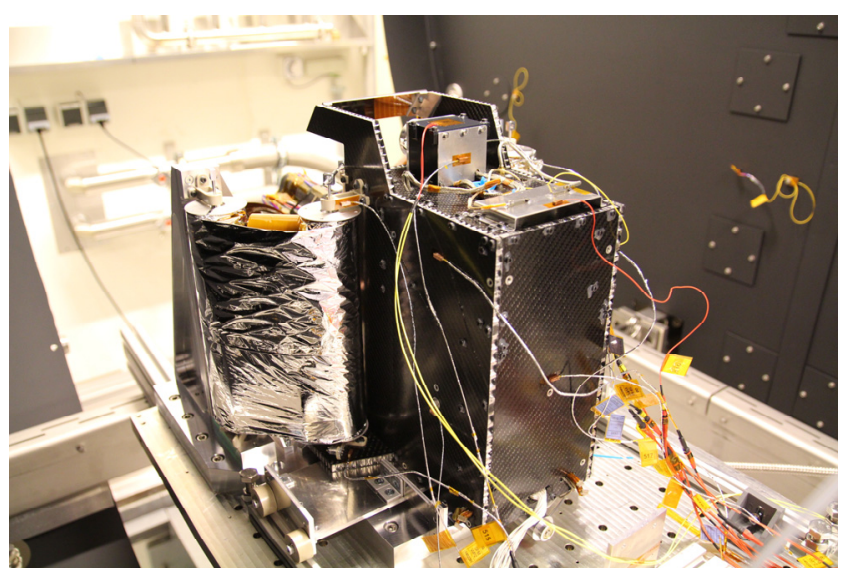

Fig. 26. Thermal vacuum EQM system level test with movable BSDU for separation testing

The planned test scenario is shown in Figure 27 and resembles a cycling test of 4 cycles which foresaw the actuation of all release mechanisms and a partial deployment in the cold phase of the third cycle. Another partial deployment was foreseen in the hot case of the last cycle. Hot operating temperature was defined at $+50{ }^{\circ} \mathrm{C}$ and cold operating temperature at $-40{ }^{\circ} \mathrm{C}$ with the motor as temperature reference point.

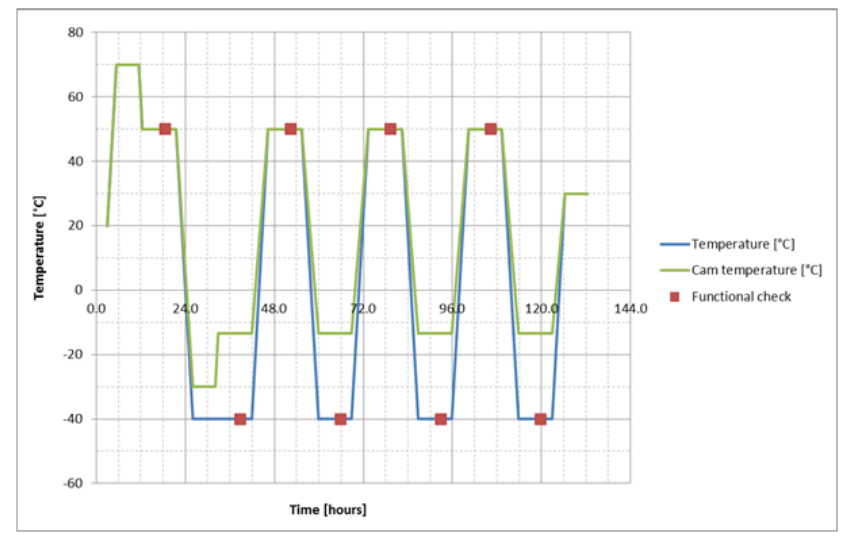

Fig. 27. Planned thermal vacuum test secquence

In a first thermal-vacuum test, cycles between roughly $+50^{\circ} \mathrm{C}$ and $-40^{\circ} \mathrm{C}$ were tested. The achieved temperature progression is shown in Figure 28. The BSDU was still mounted on the test adapter but in addition a board with rolls was mounted underneath it. On every hot and cold plateau a functional check of the electronics was made and the motor was activated but not rotated. Actual thermalvacuum deployment was not made. After the thermal cycling the hold down and release mechanisms were activated and the separation of the BSDU was executed. During the separation the BSDU rolled a few centimeters on the board.

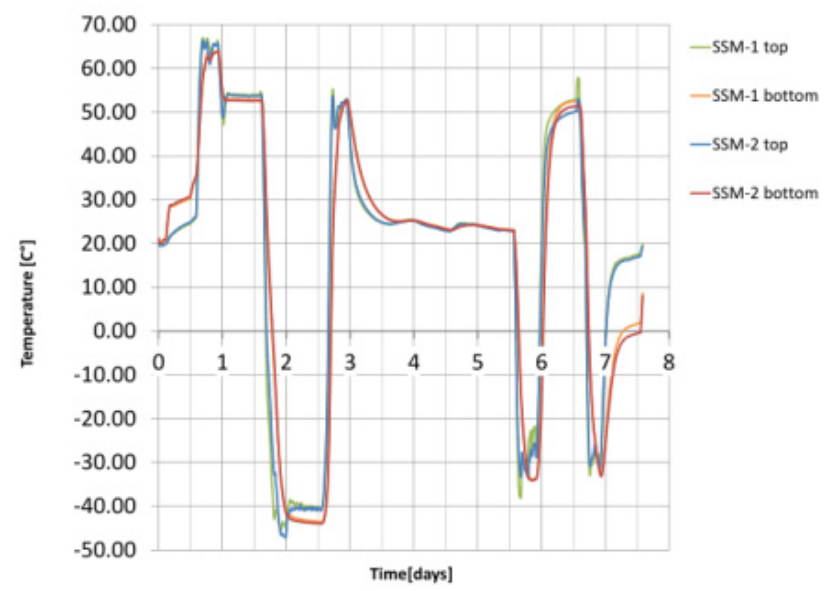

Fig. 28. Thermal vacuum temperature cycles as-run

The functional check-out of the electronics worked well and also the motor always responded. The hold down and release mechanisms all worked, but the safety cap of the frangibolt was not sufficiently sized and destroyed by the cracking bolt. The separation after the thermal cycling also worked smoothly. The deployment was afterwards continued on a deployment test rig.

Full Scale Deployment Test - The full scale deployement test is the last test for the qualification testing. Figure 29 shows the EQM BSDU with stowed sails mounted on the deployment test rig. Figure 30 shows the EQM BSDU in 
deployed configuration as well as the deployed sail segments with applied thinfilm photovoltaics or representative dummies.

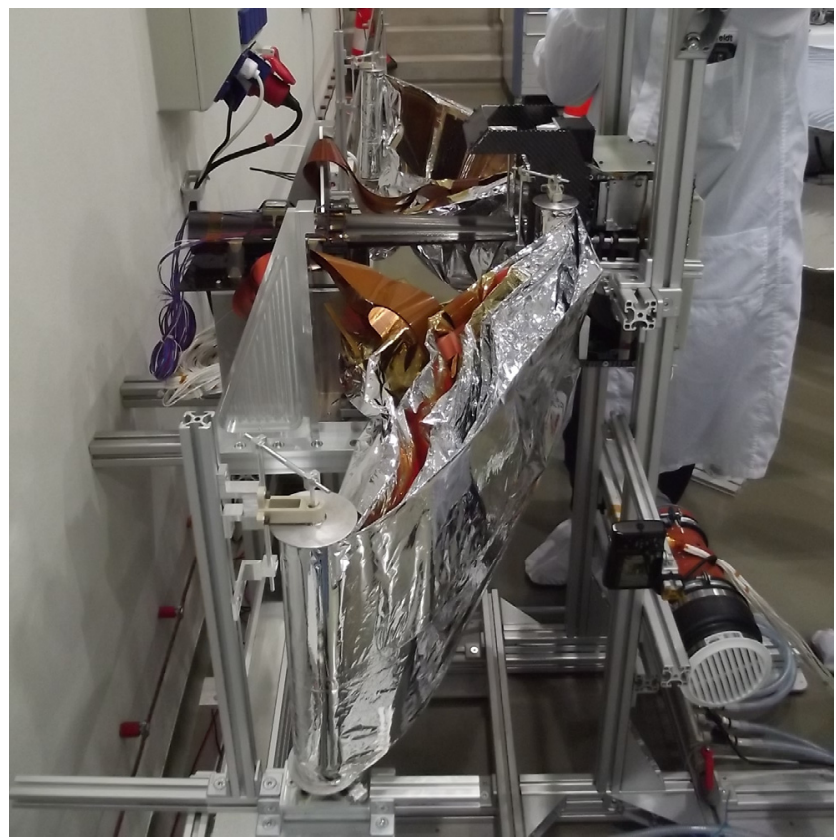

Fig. 29. EQM deployment test setup, stowed configuration

During this test a successful deployment was demonstrated. Futhermore, sail deployment loads will be measured with force gauges on the linear drives giving realistic numbers for boom loads during deployment for future sizing activities.

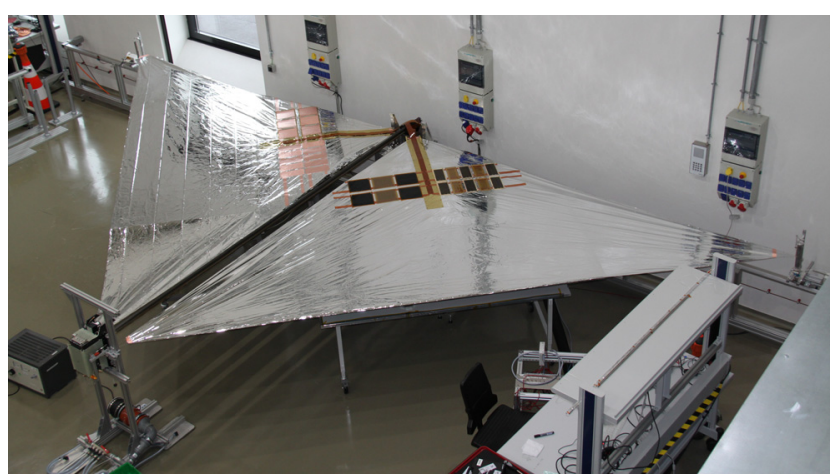

Fig. 30. EQM deployment test setup, configuration with applied photovoltaic

During the test the BSDU was commanded from the CSCU demonstrating the capability of controlling the deployment sequence by means of the common onboard computer of GOSSAMER-1.

The total deployment force measured was most of the time between $2 \mathrm{~N}$ and $3 \mathrm{~N}$, only when tensioning the sail against gravity loads at the end of the deployment these forces are increasing. The force measured during deployment on one of the sail spools is shown in Figure 31 in its components. The load was mainly directed along the boom axis. The fast oscillations present are due to the used brake mechanism for the sail spool (see [22]). At time $t_{1}$ and $t_{2}$ the deployment was interrupted in order to perform system checks. At time $t_{3}$ the support for the photovoltaic area of the sail started to carry gravity load and at $t_{4}$ the photovoltaic area was fully supported. At $t_{5}$ additional support for the sail started to carry gravity loads and at $t_{6}$ the sail was fully supported and then further tensioned until $t_{7}$.

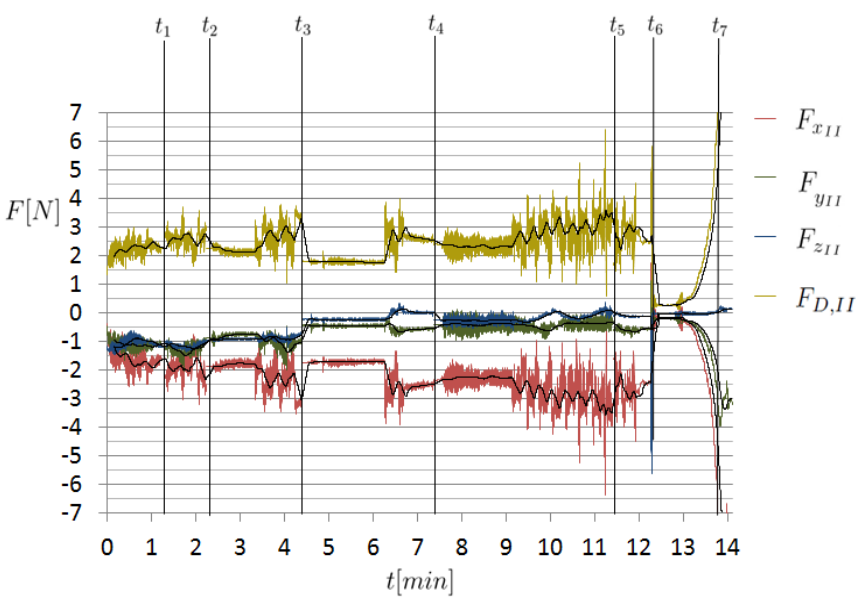

Fig. 31. Measured deployment forces

Membrane materials testing - It is known from many evaluation tests [34][35] that corpuscular and electromagnetic radiation can significantly degrade materials and lead to change of their mechanical or thermooptical properties [36]. At the DLR Institute of Space Systems, a Complex Irradiation Facility (CIF) is available, designed and commissioned with the aim to perform material investigations under simultaneous irradiation of both corpuscular and electromagnetic radiation. The facility is presented in Figure 32.

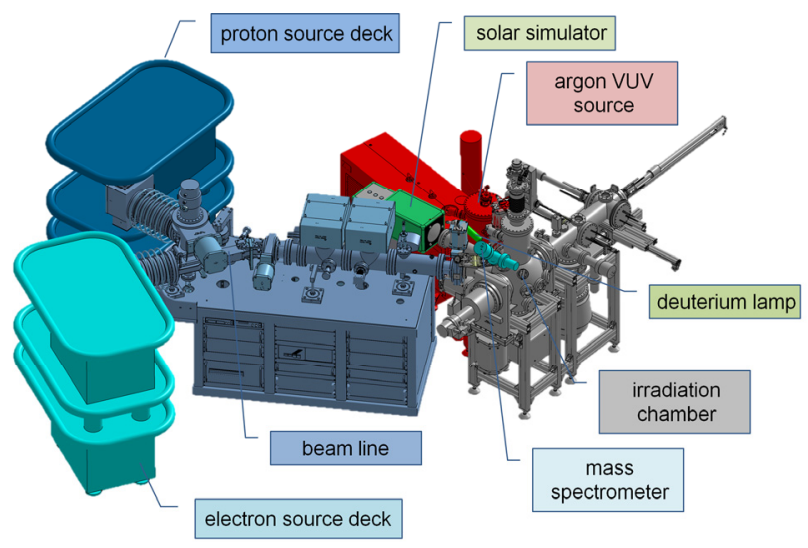

Fig. 32. Schematic view of the CIF components

The complete facility has been built in Ultra High Vacuum (UHV) technology. It is free of organic compounds to avoid self-contamination. The differential pumping system 
achieves a final pressure in the $10^{-10}$ mbar range. The CIF is equipped with electron and proton linear accelerators. The kinetic energy of both species can be set separately within a range of $1 \mathrm{keV}$ to $100 \mathrm{keV}$. The minimum achievable current of both types of particles is $1 \mathrm{nA}$ while the maximum current is $100 \mu \mathrm{A}$. Also three electromagnetic sources are available: an argon VUV source, a deuterium lamp, and a Xenon lamp. All three sources working simultaneously cover wide wavelength range from $40 \mathrm{~nm}$ to $2500 \mathrm{~nm}$ (Figure 33).

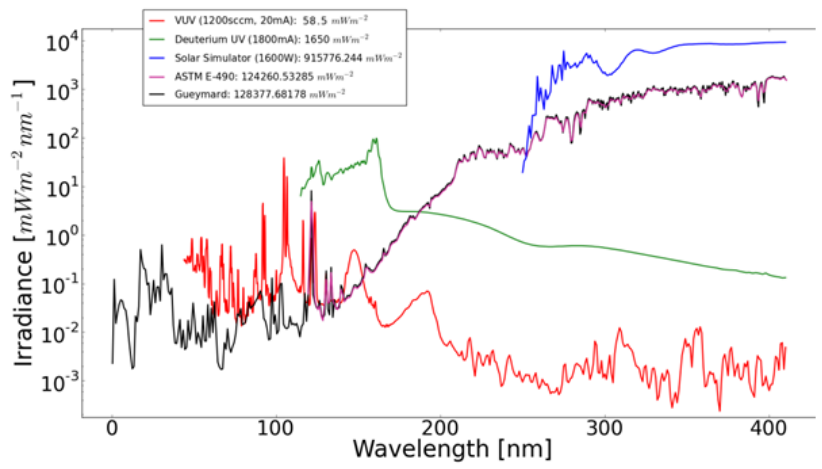

Fig. 33. The light spectra of the CIF sources compared to the solar radiation standards $[37][38]$

The CIF can irradiate materials in UHV with a wide range of temperatures. From the sample's irradiated $\alpha / \varepsilon$ equilibrium temperature, they can be artificially heated by halogen lamps to $450^{\circ} \mathrm{C}$ or cooled down to the LN2 level of $-193^{\circ} \mathrm{C}$. Low-energy corpuscular and high-energy electromagnetic radiation interacts at the immediate surface of materials.

Recently, the CIF was used in an experimental study of the formation of tiny molecular hydrogen blisters formed on vacuum-deposited Aluminum (VDA) layers. The blisters of approx. $0.4 \mu \mathrm{m}$ diameter were produced by exposure of the VDA to a flux of low energy protons at only $2.5 \mathrm{keV}$ [39]. The hydrogen gas results from recombination processes of the incident protons and the metal's electrons. The studies revealed environmental conditions, i.e. dose and kinetic energy of the incident protons as well as the temperature of the specimens, at which the blistering process takes place. Formation of the blisters has a major impact on reflectivity of the VDA which has a broad application in the thermal insulation foils and membranes of lightweight deployable structures like solar sails. A foil exposed to a flux of 2.5 $\mathrm{keV}$ protons is shown in Figure 34. The upper picture presents the spot area - the place where the protons hit the surface - in light gray color. The bottom picture shows an electron microscope picture of the spot. One can recognize a number of small blisters present on the surface.

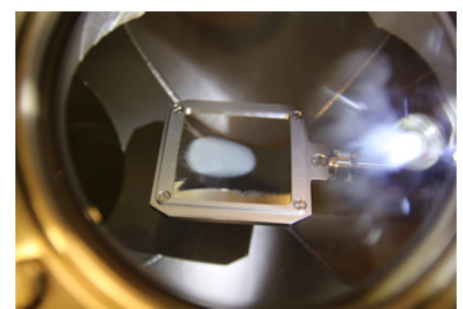

(a) CIF irradiated spot, light gray area

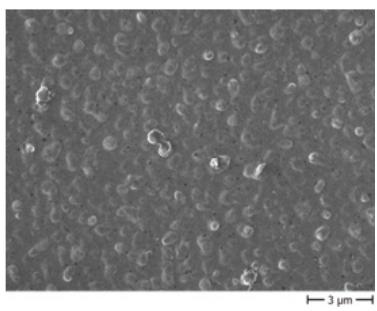

(b) electron microscope picture of the VDA surface in the spot
Fig. 34. CIF-irradiated foil sample

\section{Gossamer Solar Sail Performance}

With the GOSSAMER-1 technology, the pure sail mass (membrane and booms) as a function of the edge length of the rectangular sail is given in Figure 35 . The mass of the booms used for the $(5 \mathrm{~m})^{2}$ GOSSAMER-1 project is $40 \mathrm{~g} / \mathrm{m}$. For GOSSAMER-2 with $(20 \mathrm{~m})^{2}$ it is expected to be $90 \mathrm{~g} / \mathrm{m}$ and for a GOSSAMER-3 of $(50 \mathrm{~m})^{2}, 150 \mathrm{~g} / \mathrm{m}$. The boom mass for differently sized sails is linearly interpolated and extrapolated for bigger sails. The mass of the membrane includes $7.5 \mu \mathrm{m}$ polyimide film and the required amount of adhesive for the considered sail size. Note that thinner films were considered for GOSSAMER-2 and expected for GOSSAMER-3, cf. Table 2.

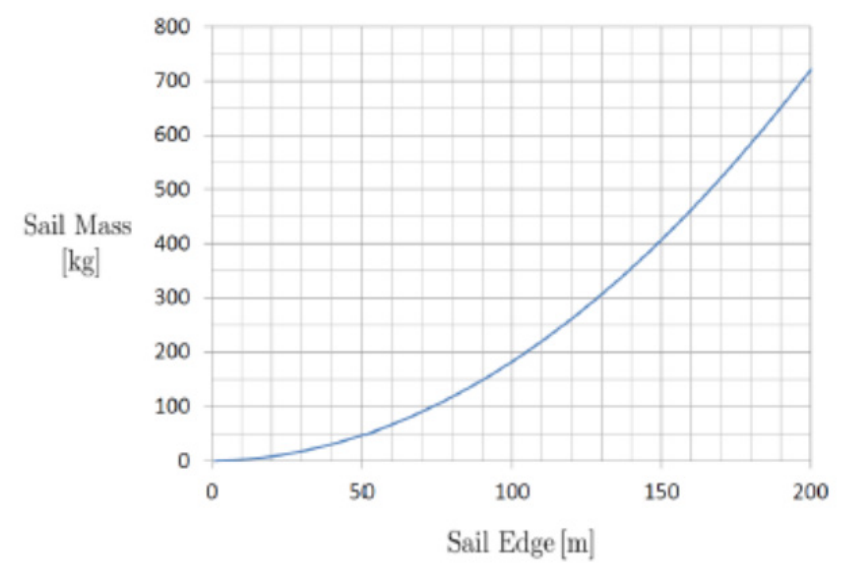

Fig. 35. Sail mass as a function of the edge length of the rectangular sail

An often used performance parameter of solar sail is the characteristic acceleration. It is the acceleration which it would be present at 1 AU distance from the Sun when perpendicular irradiated. With the mass estimation, it is possible to also estimate the characteristic accelerations as shown in Figure 36. The characteristic acceleration is calculated for a reflectivity of $90 \%$.

Missions considering Multiple Near Earth Asteroid (NEA) Rendezvous (MNR) as recently proposed in [40][41][42] and anticipated by the GOSSAMER Roadmap Science Mission Working Groups [43][44][45] would require sails 
with an characteristic acceleration between 0.1 and 0.2 $\mathrm{mm} / \mathrm{s}^{2}$. This can be achieved by sails with an edge length of about $30 \mathrm{~m}$ considering a bus and payload mass of about 50 $\mathrm{kg}$. While further development is of course required, this is possible with the sail technology available.

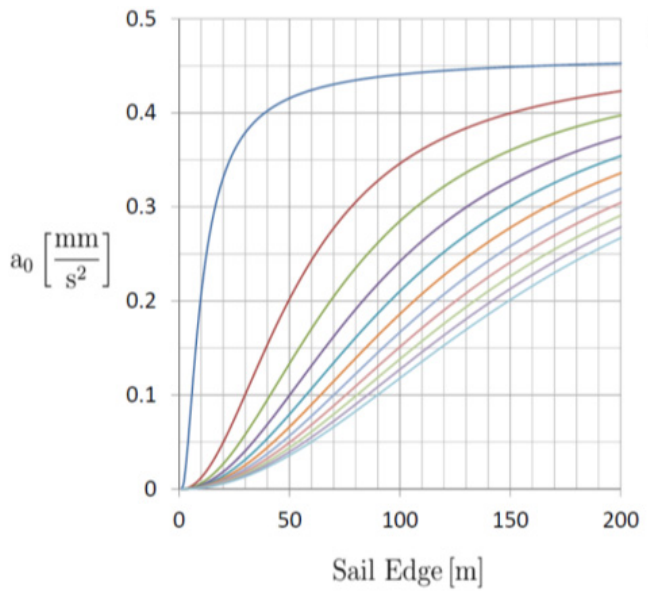

Bus + Payloadl

$-0 \mathrm{~kg}$

$-50 \mathrm{~kg}$

$-100 \mathrm{~kg}$

$-150 \mathrm{~kg}$

$-200 \mathrm{~kg}$

$-250 \mathrm{~kg}$

$-300 \mathrm{~kg}$

$-350 \mathrm{~kg}$

$-400 \mathrm{~kg}$

Fig. 36. Characteristic acceleration for different masses of bus and payload. This mass is considered in addition to the sail mass

We report on some of the options to design MNR missions and nano-landers carried by solar sails in [46][47][48].

\subsection{Operational Considerations}

The separation of the BSDUs is an important factor in the high performance of GOSSAMER-style solar sails. This design feature requires some additional operational considerations regarding their launch and disposal.

While every GOSSAMER-style small spacecraft solar sail is composed of 5 essentially independent small spacecraft, they need to operate as one to facilitate the use of currently available secondary payload ("piggy-back") launch opportunities for small spacecraft. [48][49] In the launch configuration, the CSCU and the 4 BSDUs are connected by wired interfaces routed through the umbilical connectors jointly developed with MASCOT. The relatively low power wireless interfaces are checked out before integration to the launcher but could also still be tested on the launcher if allowed by the launch provider and the main payload(s). Also, the structural connections between the 5 subspacecraft create a combined spacecraft able to handle launch loads, designed with launcher flexibility in mind.

The BSDUs continue on ballistic trajectories after deployment of the membrane and separation from the boom tips. In a low Earth orbit mission like GOSSAMER-1, re-entry according to space debris avoidance rules has to be ensured. For the envisaged orbits of the analyzed launch options of QB50 with GOSSAMER-1, the orbital lifetime of the BSDUs was between a few months to about 10 years, based on nominal spaceweather predictions. The development missions to follow, GOSSAMER-2 and -3 , were envisaged to operate in a high orbit outside of the LEO zone (i.e., $>2000$ $\mathrm{km}$ altitude) or beyond GEO, respectively. Deployment at the 25 year orbital lifetime limit altitude of the BSDUs followed by spiral-up of the sail is possible but results in a rather long time spent in the radiation belts until Earth escape is achieved. For the envisaged science missions [43][44][45], a launch to GTO followed by a small kickstage burn to $c_{3}=0$ was tentatively baselined. In this case, the separated BSDUs would slowly escape the EarthMoon system.

The BSDUs and for a brief period also the accelerating sail form a slowly expanding constellation which lends itself to a number of secondary experiments carried mainly on the BSDUs but also involving sail payloads, ranging from magnetospheric and heliospehric studies to radio amateur experiments.

\section{CONCLUSION AND OUTLOOK}

A deployment strategy was developed for a mission that aims to demonstrate a controlled and autonomous deployment in LEO. For this deployment strategy, a bus system as well as the required deployment mechanisms and electronics were developed, and engineering models of the hardware were built.

Deployment on system level was successfully demonstrated to be robust, controllable, and at no time at risk of entangling. The latter is guaranteed by the folding concept, which ensures that at each stage of deployment, only a minimum amount of the sail is released. The boom, BSI and BSDU proved to be suitable to drive the combined deployment of booms and sails. No negative interference between boom deployment and sail deployment was observed. The functionality of all involved mechanisms was demonstrated. The functionality of the electronics was demonstrated, i.e. wireless control, deployment logic implemented, data acquisition, image acquisition by the onboard camera and a ground segment representative control via the electronics ground support equipment. A more detailed overview about the GOSSAMER-1 mission, hardware and verification is provided in [22].

The deployment technology is on TRL five, after EQM environmental testing. The EQM of the deployment unit was successfully subjected to vibration testing, venting testing, thermal vacuum and laboratory deployment testing.

The development of the solar sail specific technology was stopped after the qualification process on a TRL five. The further development of deployment technologies will focus on solar arrays based on thin-film photovoltaics. A DLR internal research programme GoSOLAR (Gossamer Solar Array) is initiated to develop a $(5 \mathrm{~m})^{2}$ deployment demonstrator with experimental thin-film photovoltaics. It is scheduled for an in-orbit demonstration on the second mission of the small satellite platform of DLR called 
S2TEP. The mission is considered to be launched in 2022 where for demonstration purposes the solar array shall provide power to the satellite bus as an experiment.

Future goal is the development of arrays with a power output of up to $50 \mathrm{~kW}$ at $(20 \mathrm{~m})^{2}$ for missions using electric propulsion.

\section{ACKNOWLEDGEMENTS}

This work was funded by DLR's Research and Development program Technology for Space Systems as "Gossamer-1 Deployment Technology Demonstrator Project". The launch opportunity was funded by EC-Project "QB50", Project Identifier 284427, FP7-SPACE-2011-1, "QB50-An international network of 50 CubeSats for multipoint, in-situ measurements in the lower thermosphere and re-entry research". The authors appreciated the fruitful and constructive cooperation with all QB50 and EC representatives.

The authors wish to express their gratitude for excellent technical discussions, review support and advice by ESA/ESTEC-TEC-M and D/TEC-MTT. Regarding solar sail specific mission design the authors are indebted to ESA ESTEC TEC-M for organizational support and to Bernd Dachwald (University of Applied Sciences Aachen), Malcolm Macdonald (University of Strathclyde) and Collin McInnes (University of Glasgow) for leading three independent solar sail candidate mission studies. Furthermore, the authors want to thank their project partners at University of Würzburg, Aerospace Information Technology as well as at RWTH Aachen, Institute of High Frequency Engineering for fruitful cooperation and discussion.

And finally our thoughts are with late Rüdeger Reinhard, together with Jean Muylaert from VKI Brussels one of the godfathers to QB50 and GOSSAMER-1 within QB50. As ESA Consultant, Rüdeger's everlasting initiative and diplomacy brought people together, brought projects into existence and without him this project would never have reached the stage of maturity, which it has reached by now, no matter, which obstacles still pertain. He inspired people and created visions. The world needs more people of this kind. Instead, we grieve for him, having one less of his kind among us.

\section{REFERENCES}

[1] Leipold, M., et al., ODISSEE - A proposal for demonstration of a solar sail in earth orbit, Acta Astronautica, Vol. 45/4, 557-566, 1999.

[2] Agnolon D., Study overview of a solar sail demonstrator: GEOSAIL, DLR/ESA, 2008.

[3] Leipold, M., Eiden, M., Garner, C. E. et al., Solar sail technology development and demonstration, Acta Astronautica Vol. 52(2), 317-326, 2003.

[4] Leipold, M., Widani C., et al., The European Solar Sail Deployment Demonstrator Mission, Proceedings of the International Astronautical Congress, 2006.

[5] T. Spröwitz, P. Seefeldt, et al., Design of the Gossamer-1 Deployment Demonstrator. Proceedings of the Fourth International Symposium on Solar Sailing, 2017

[6] U. Geppert, B. Biering, F. Lura, J. Block, R. Reinhard, The 3-Step DLR-ESA Gossamer Roadmap to Solar Sailing, ISSS, New York, 2010

[7] U. Geppert, B. Biering, F. Lura, J. Block, et al., The 3Step DLR-ESA GOSSAMER road to solar sailing, Advances in Space Research 48 (2011) 1695-1701

[8] C. Grimm, et al., DLR MASCOT on HAYABUSA-II, A Mission That May Change Your Idea of Life! - AIV Challenges in a Fast Paced and High Performance Deep Space Project, submitted, sr104H00604H, ISTS 2013

[9] J.T. Grundmann, V. Baturkin, et al., "You've got 2 Years, 6 Months, 1 Week and 48 Hours!" - the Ongoing Engineering Adventure of MASCOT and its Implications for Planetary Defence Missions, IAA-PDC13-04-06P, $3^{\text {rd }}$ IAA Planetary Defense Conference, PDC 2013, Flagstaff.

[10] C.D. Grimm, J.T. Grundmann, J. Hendrikse, On Time, On Target - How the Small Asteroid Lander MASCOT Caught a Ride Aboard HAYABUSA-2 in 3 Years, 1 Week and 48 Hours, IAA-PDC15-P-66, $4^{\text {th }}$ IAA Planetary Defense Conference - PDC 2015, Frascati, Italy

[11] C.D. Grimm, J.T. Grundmann, J. Hendrikse, et al., Going Beyond the Possible, Going Beyond the "Standard" of Spacecraft Integration and Testing! - A Summary of the DLR Mascot AIV Activities within the Hayabusa2 Project from the First Unit Hardware Test to Final Check-out before Launch - $30^{\text {th }}$ ISTS 2015

[12] Miura K.: Method of packaging and deployment of large membranes in space, Proceedings of the $31^{\text {st }}$ Congress International Astronautical Federation, 1985

[13] Seefeldt, P., Steindorf, L. Sproewitz, T., Solar Sail Membrane Testing and Design Considerations, Proceedings of the European Conference on Spacecraft Structures, Materials and Environmental Testing, 2014. 
[14] Guest, S. D., and Pellegrino, S: Inextensional wrapping of flat membranes, Proceedings of the First International Seminar on Structural Morphology (pp. 203-215), 1992.

[15] De Focatiis, D. S. A., \& Guest, S. D.: Deployable membranes designed from folding tree leaves, Philosophical Transactions of the Royal Society of London A: Mathematical, Physical and Engineering Sciences, 360(1791), 227-238, 2002.

[16] Stohlman, O. R., Fernandez, J., et al., Testing of the Deorbitsail drag sail subsystem, Proceedings of the $54^{\text {th }}$ AIAA/ASME/ASCE/AHS/ASC Structures, Structural Dynamics, and Materials Conference, 2013

[17] Tsuda Y., Mori, O., Funase, R. et al., Achievement of IKAROS - Japanese deep space solar sail demonstration mission, Acta Astronautica, Vol. 82/2, 183-188, 2013.

[18] Wolff, N., Seefeldt, P., Bauer et al.: Alternative application of solar sail technology, Advances in Solar Sailing (pp. 351-365), Springer, Berlin Heidelberg, 2014.

[19] P. Seefeldt. A stowing and deployment strategy for large membrane space systems on the example of Gossamer-1. Advances in Space Research 60.6 (2017): 1345-1362, 2017

[20] P. Seefeldt, P. Spietz, T. Spröwitz et al. Controlled Deployment of Gossamer Spacecraft. Proceedings of the Fourth International Symposium on Solar Sailing, 2017

[21] Johnson, L., Whorton, M., Heaton, A., Pinson, R., Laue, G. et al., NanoSail-D: A solar sail demonstration mission, Acta Astronautica Vol. 68(5), 571-575, 2011.

[22] P. Seefeldt, P. Spietz, T. Spröwitz et al. Gossamer-1: Mission concept and technology for a controlled deployment of gossamer spacecraft. Advances in Space Research 59.1 (2017): 434-456, 2017.

[23] Thoemel, J., Singarayar, F., Scholz, T. et al., Status of the QB50 CubeSat Constellation Mission, Proceedings of the $65^{\text {th }}$ International Astronautical Congress, 2014.

[24] Seefeldt, P., et al., The Preliminary Design of the GOSSAMER-1 Solar Sail Membrane and Manufacturing Strategies, Advances in Solar Sailing, 133-151, 2014.

[25] J.T. Grundmann, et al., GOSSAMER Deployment Systems for Flexible Photovoltaics, Proceedings of the $67^{\text {th }}$ International Astronautical Congress (IAC), ISBN 9781510835825, 2016, IAC-16-C3.3.6

[26] Straubel, M., Seefeldt, P., Spietz, P. and Hühne C., The Design and Test of the GossAMER-1 Boom Deployment Mechanisms Engineering Model, Proceedings of the $2^{\text {nd }}$ AIAA Spacecraft Structures Conference, 2015.
[27] P. Seefeldt and P. Spietz. RaumfahrzeugMembranentfaltungssystem und Verfahren zum Betrieb desselben. Patent 102016101 430.3, Patent Filed 2016

[28] Zander, M. E., Sinapius M, and Hühne, C., Preliminary Experiments for an On-Orbit Detection system to Monitor Load and Deflection States of Thin Shell CFRP Booms for the Solar Sail Demonstrator GosSAMER-1, Proceedings of the European Conference on Spacecraft Structures, Materials and Environmental Testing, 2014.

[29] Seefeldt, P., Spröwitz, T., et al., "Verification Testing of the Gossamer-1 Deployment Demonstrator" Proceedings of the $67^{\text {th }}$ International Astronautical Congress (IAC), ISBN 9781510835825, 2016, IAC-16-C2.2.3

[30] P. Seefeldt and T. Spröwitz. Qualification Testing of the Gossamer-1 Deployment Technology. Proceedings of the $14^{\text {th }}$ European Conference on Spacecraft Structures, Materials and Environmental Testing, 2016

[31] Ho, T., Baturkin, V., Grimm, C., et al., MASCOT - The Mobile Asteroid Surface Scout Onboard the HAYABUSA2 Mission, Space Science Reviews, Vol. 1-36, 2016.

[32] Straubel, M., Seefeldt, P., Spietz, P. and Hühne C., The Design and Test of the GosSAMER-1 Boom Deployment Mechanisms Engineering Model, Proceedings of the $2^{\text {nd }}$ AIAA Spacecraft Structures Conference, 2015

[33] ECSS-E-ST-01C, The European Cooperation for Space Standardization, 2009

[34] ASTM, E512-94, Standard Practice for Combined, Simulated Space Environment Testing of Thermal Control Materials with Electromagnetic and Particulate Radiation, 2010.

[35] ECSS-Q-ST-70-06C, Particle and UV Radiation Testing for Space Materials, 2008.

[36] B. Dachwald, M. Macdonald, et al., Impact of optical degradation on solar sail mission performance, Journal of Spacecraft and Rockets, vol. 44, 2007, pp. 740-749.

[37] C.A. Gueymard, The sun's total and spectral irradiance for solar energy applications and solar radiation models, Solar Energy, vol. 76, 2004, pp. 423-453.

[38] ASTM, E490-00a, Solar Constant and Zero Air Mass Solar Spectral Irradiance Tables, reapproved 2006.

[39] M. Sznajder, U. Geppert, M. Dudek, Degradation of metallic surfaces under space conditions, with particular emphasis on Hydrogen recombination processes, Advances in Space Research, vol. 56, 2015, pp. 71-84.

[40] Sullo, N., Peloni, A. and Ceriotti, M., "Low-Thrust to Solar-Sail Trajectories: A Homotopic Approach”, Journal of Guidance, Control, and Dynamics, Vol. 40, No. 11, 2017, pp. 2796-2806. doi: 10.2514/1.G002552 
[41] Peloni, A., Dachwald, B., Ceriotti, M., "Multiple NearEarth Asteroid Rendezvous Mission: Solar-Sailing Options", accepted for publication in Advances in Space Research, 2017.

[42] A. Peloni, M. Ceriotti, B. Dachwald, Solar-Sail Trajectory Design for a Multiple Near-Earth-Asteroid Rendezvous Mission, Journal of Guidance, Control, and Dynamics, Vol. 39, No. 12, 2016, pp. 2712-2724, DOI: 10.2514/1.G000470

[43] B. Dachwald, H. Boehnhardt, U. Broj, U.R.M.E. Geppert, et al. Gossamer Roadmap Technology Reference Study for a Multiple NEO Rendezvous Mission, Advances in Solar Sailing, Springer Praxis 2014, pp 211226. ( $3^{\text {rd }}$ International Symposium on Solar Sailing)

[44] C.R. McInnes, et al. Gossamer Roadmap Technology Reference Study for a Sub-L1 Space Weather Mission, in: M. Macdonald (ed.), Advances in Solar Sailing, 2014 (3 ${ }^{\text {rd }}$ International Symposium on Solar Sailing)

[45] M. Macdonald, C. McGrath, et al., Gossamer Roadmap Technology Reference Study for a Solar Polar Mission, in: M. Macdonald (ed.), Advances in Solar Sailing, 2014 ( $3^{\text {rd }}$ International Symposium on Solar Sailing)

[46] J.T. Grundmann, et al., Soil to Sail - Asteroid Landers on Near-Term Sailcraft as an Evolution of the GOSSAMER Small Spacecraft Solar Sail Concept for InSitu Characterization, IAA-PDC-17-05-19, $5^{\text {th }}$ IAA Planetary Defense Conference, 2017, Tokyo, Japan.

[47] J.T. Grundmann, W. Bauer, J. Biele, et al., Small Spacecraft SolarSailing for Small Solar System Body Multiple Rendezvous and Landing, this conference.

[48] J.T. Grundmann, W. Bauer, J. Biele, R. Boden et al., Capabilities of GOSSAMER-1 derived Small Spacecraft Solar Sails carrying MASCOT-derived Nanolanders for In-Situ Surveying of NEAs, Acta Astronautica - Special Issue: Planetary Defence 2018 (submitted: under review)

[49] C. Lange, et al., Exploring Small Bodies: Nanolander and -spacecraft options derived from the Mobile Asteroid Surface Scout, Advances in Space Research, 2018 (submitted: under review)

\section{BIOGRAPHY}

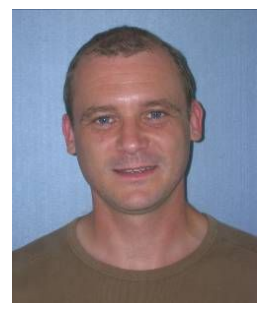

Tom Sproewitz is head of the department Mechanics and Thermal Systems of the DLR Institute of Space Systems since 2012. In 2001 he graduated at the Technical University Chemnitz, Germany with a Diploma in Applied Mechanics as part of Mechanical Engineering. After graduation he worked at the DLR Institute of Composite Structures and Adaptive Systems as mechanical engineer until 2009. He was involved in the development, manufacturing and mechanical testing of the ROSETTALander PHILAE as Mechanical Analysis Engineer. 2009 he works at the Institute of Space Systems in Bremen with focus on structures, mechanisms, deployment systems as well as environmental testing. He worked as structural engineer on the DLR payload HP3 as part of the NASA/JPL Mission to Mars, INSIGHT.

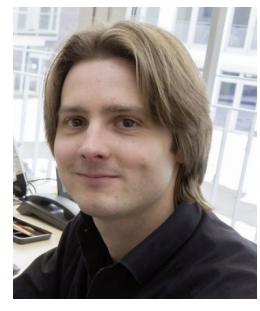

Patric Seefeldt is pursuing a Ph.D. at $D L R$ and the University of Bremen on Development and Qualification Strategies for Deployable Membrane Spacecraft Systems. He works in the projects GOSSAMER-1 and GOSOLAR at the DLR Institute of Space Systems in Bremen, Germany. He studied mechanical engineering at the RWTH Technical University of Aachen, Germany, where he worked as a research associate at the Institute of Structural Mechanics and Lightweight Design.

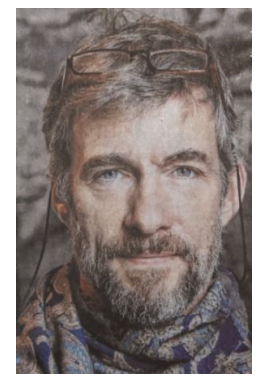

Peter Spietz is working on the technological development and adaptation of the membrane-based photovoltaics of GOSSAMER-1 for the project GOSOLAR at the DLR Institute of Space Systems in Bremen, Germany. He was project manager and system engineer of GOSSAMER-1 and the first DLR Research \& Development 'Kompaktsatellit' project, ASTEROIDFINDER/SSB for which he also led the Phase 0 competitive studies of the payloads CHARM and LIVESAT. Previously, he worked at the Institute of Environmental Physics (IUP) of the University of Bremen on the GOME ozone monitoring instrument series.

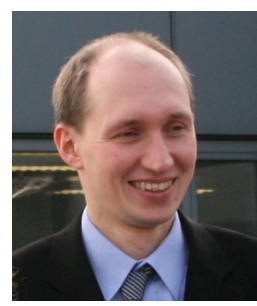

Jan Thimo Grundmann is a research engineer at DLR for $10^{1 / 2}$ years. He received a Diploma in Mechanical Engineering - Aerospace Engineering from the RWTH Technical University of Aachen, Germany, in 2006. He works in the projects MASCOT, MASCOT2, GOSSAMER-1, GOSOLAR, and ROBEX. He supports system engineering in these projects, related 
studies, and at the DLR Bremen CEF on electrical topics. He is also pursuing system studies in planetary defence, spacecraft reliability and space project responsiveness.

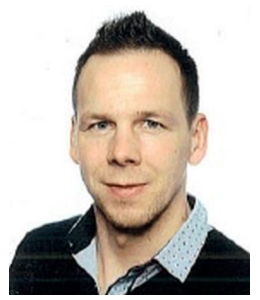

Rico Jahnke received his diploma in mechanical engineering and aerospace engineering from the University of Applied Sciences of Aachen in 2010 and joined DLR. Currently, he is deputy head of the Mechanical Dynamical Test Laboratory at the DLR Institute of Space Systems, Bremen, Germany. He works on the technological development of membrane-based deployment systems in the GOSSAMER-1 and GOSOLAR projects at the DLR Institute of Space Systems in Bremen, Germany.

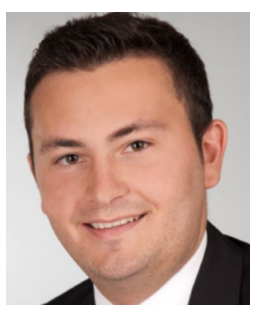

Eugen Mikulz is the main responsible person for the environmental testing at the DLR Institute of Space Systems in Bremen, Germany. He studied production engineering with the specialization in aerospace at the University of Bremen and reached his Master of Science degree. He was involved in the thermal vacuum or ambient testing in projects like Gossamer, ADEO, MASCOT, INSIGHT and ENMAP.

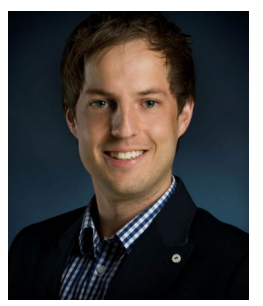

Siebo Reershemius received his Master Degree in Mechanical Engineering in 2010 and joined the DLR Institute of Space Systems in Bremen, Germany, as a research engineer. His main interests are deployable structures and mechanisms. He was engineer for structural analysis and mechanism development of the institute's first satellite, AISAT-1, launched in 2013, and is lead of the HP Support System, which is part of the DLR instrument HP aboard the NASA mission INSIGHT to be launched in 2018. Currently, he works on the technological development of membrane-based deployment systems in the GOSSAMER-1 and GOSOLAR projects.

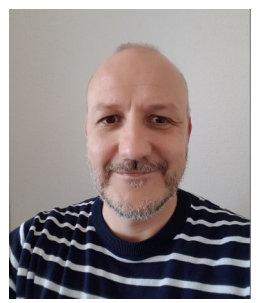

Thomas Renger is the head of the Complex Irradiation Facility (CIF) at DLR Bremen. He is working in the design, commissioning, and operation of the facility and the execution of material degradation experiments. He has studied electrical engineering at the University of Rostock and joined the

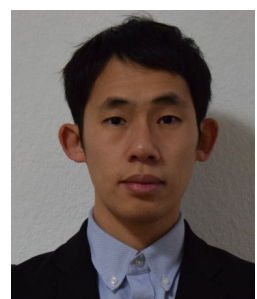

Kaname Sasaki received his Master degree in Aerospace Engineering from Tokyo University, Japan. Since 2013 he works at the department of Mechanics and Thermal Systems of the DLR Institute of Space Systems in Bremen, Germany. He has been involved in the development and testing activities for the asteroid lander MASCOT, the DLR payload $H P^{3}$ as part of the NASA/JPL Mission INSIGHT and the membrane-based deployment systems in the GOSSAMER-1. Currently, he works as a system engineer of the MASCOT project, as well as a thermal engineer in the GOSOLAR project.

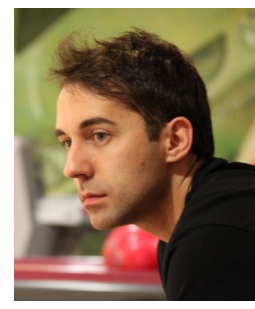

Maciej Sznajder is a scientific coworker at the department Mechanics and Thermal Systems of the DLR Institute of Space Systems. In 2010 he graduated computational astrophysics at the University of Zielona Góra, Poland. In 2013 he defended Ph.D. in theoretical physics at the University of Zielona Góra and in 2016 a Ph.D. in materials engineering at the Bremen University, Germany. Since 2010, he works in a field of materials degradation mechanisms which take place under space conditions. Currently, he is involved in the technological development of membrane-based deployment systems in the GOSSAMER-1 and GOSOLAR projects at the DLR Bremen.

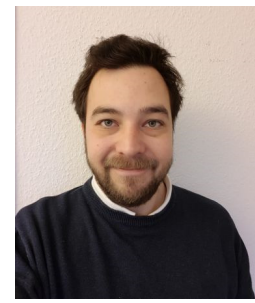

Norbert Tóth has studied electrical engineering at the Óbuda University in Hungary. He is working since 2010 at DLR Bremen in the department Avionics Systems. His main interests are embedded system design, $H W \& S W$ development and wireless communication for Space Systems. He was the work packet leader (Command and Data Handling, CDH) for GOSSAMER-1 and for ROBEX Lander and Remote Unit. Currently he is working on the GOSOLAR CDH and on the MASCOT checkout, operations. 